\title{
A renewable energy and hydrogen scenario for northern Europe
}

\section{Sørensen, Bent}

Published in:

International Journal of Energy Research

DOI:

10.1002/er.1376

Publication date:

2008

Document Version

Early version, also known as pre-print

Citation for published version (APA):

Sørensen, B. (2008). A renewable energy and hydrogen scenario for northern Europe. International Journal of Energy Research, 32(5), 471-500. https://doi.org/10.1002/er.1376

\section{General rights}

Copyright and moral rights for the publications made accessible in the public portal are retained by the authors and/or other copyright owners and it is a condition of accessing publications that users recognise and abide by the legal requirements associated with these rights.

- Users may download and print one copy of any publication from the public portal for the purpose of private study or research.

- You may not further distribute the material or use it for any profit-making activity or commercial gain.

- You may freely distribute the URL identifying the publication in the public portal.

\section{Take down policy}

If you believe that this document breaches copyright please contact rucforsk@kb.dk providing details, and we will remove access to the work immediately and investigate your claim. 


\title{
A renewable energy and hydrogen scenario for northern Europe
}

\author{
Bent Sørensen* \\ Roskilde University, Department of Environmental, Social and Spatial Change,Energy Environment and Climate Research Group \\ Universitetsvej 1, Bld. 11.2, PO Box 260, DK-4000 Roskilde, Denmark
}

\begin{abstract}
SUMMARY
A scenario based entirely on renewable energy with possible use of hydrogen as an energy carrier is constructed for a group of North-European countries. Temporal simulation of the demand-supply matching is carried out for various system configurations. The role of hydrogen technologies for energy storage and fuel cell applications is studied and applied to both stationary energy use and transportation sectors. As an alternative, biofuels may take the role of hydrogen both as a storable fuel and for direct use in the transportation sector. It is shown that there is scope for considerable amounts of energy trade between the countries, due to the different endowment of different countries with particular renewable energy sources, and to the particular benefit that intermittent energy sources such as wind and solar can derive from exchange of power. The establishment of a smoothly functioning renewable energy supply system is demonstrated with use of the seasonal reservoir-based hydro components in the northern parts of the region. The outcome of the competition between biofuels and hydrogen in the transportation sector is dependent on development of viable fuel cells and on efficient technologies for converting biomass residues to fuels.
\end{abstract}

KEY WORDS: scenario technique, energy modelling, simulation, renewable energy

\section{INTRODUCTION}

The first study suggesting that all energy needs in society could be derived from renewable resources was put forward several decades ago by Sørensen (1975). That study also constituted the first use of the scenario technique to the energy sector, and was one of the first demonstrations of the role that hydrogen can play as an energy carrier and storage medium. Other suggestions of an important role for hydrogen in future energy systems were put forward during the early 1970ies, e.g. by Marchetti (1973), Bockris (1972) and Veziroglu (1975), but mostly based on supply from non-renewable resources such as nuclear energy.

The development of the energy scenario method has gone through a sequence of increasingly wellfounded and detailed models of the functionality and consistency of the energy systems found worthy of study. In particular, the procurement of realistic data on future availability of various energy sources and the mapping of technology progress towards higher energy conversion efficiency have advanced considerably. Some recent studies are described in Nielsen and Sørensen, (1998), Sørensen and Meibom (2000), and in Sørensen (2004, 2005). The present study is connected to an ongoing project on the relationship between hydrogen and energy trade (Sørensen et al., 2007), aimed at studying the roles of energy trade and large-scale hydrogen storage in an all renewable energy-hydrogen energy system for Denmark and the neighbouring countries with which energy trade is already established (Norway, Sweden, Finland and Germany).

- email: boson@ruc.dk, website: http://energy.ruc.dk 
A number of energy demand scenarios has been formulated, as described in the adjacent article (Sørensen, 2007a). For the present study, the middle scenario (described in section 3.2.2 of Sørensen, 2007a) is used, as regards the year 2060 status of implementing efficiency improvements and particularly with respect to the development of human activities in the countries concerned. The energy demand assumed in 2060 for the five countries involved are shown in Figures 1-5, reflecting variations between countries due to different intensity of industry and different climatic conditions affecting building heat losses. It is assumed that the much larger demand differences existing today will decline in a future where energy transmission and trade has eliminated the large energy price variations of the historical energy system. The liberalisation of transmission and exchange business environments has already achieved a considerable move towards consistent pricing.

The primary renewable energy sources are wind power (on- and off-shore) for regions with a fairly open coastline, hydropower for regions with suitable mountains and biofuels for the regions with either agricultural or forestry production. Only residues from cultivation activities are considered for energy purposes, in order not to interfere with food production or alter forest coverage. However, aquaculture in near-shore locations is also considered, as this is seen as an important potential source for additional biofuels in the future. Whether a competition with food production over such off-shore areas will emerge depends on the global population growth, but even so, one could again restrict the energy use of biomass to the residues from aquaculture food production. Finally, solar energy used for electricity or heat production is considered for the southern part of the region under study (i.e. Germany), because further north, the seasonal mismatch between solar radiation and energy demand (especially for space heating) is likely to make solar solutions remain too expensive. Small contributions to solar hot-water production in summer and other sources such as geothermal have been omitted because their contribution is likely to remain small, even 50 years into the future.

Table 1. Potential renewable energy supply available for use in the North-European countries considered (unit PJ/y). PVT is combined photovoltaic and thermal collectors.

\begin{tabular}{llllll}
\hline Country: & DK & N & S & SF & D \\
\hline Wind on-shore & 64 & 167 & 201 & 147 & 157 \\
Wind off-shore & 358 & 974 & 579 & 391 & 177 \\
Biofuels from agriculture & 241 & 51 & 111 & 49 & 1993 \\
Biofuels from forestry & 58 & 523 & 1670 & 1180 & 892 \\
Biofuels from aquaculture & 153 & 223 & 320 & 205 & 108 \\
Hydro & - & 510 & 263 & 49 & 27 \\
Solar PVT electricity & - & - & - & - & 129 \\
Solar PVT heat & - & - & - & - & 275 \\
\hline
\end{tabular}

The energy sources that could be employed in a sustainable way and with acceptable social and environmental impacts are summarised in Table 1. The wind potential on land is derived from reanalysis data ensuring measurement consistency by use of global circulation modelling (Kalney et al., 1996), and assuming a wind turbine density similar to the one presently existing in Denmark, but using contemporary multi-megawatt units. The wind potential off-shore is estimated from satellite scatterometer data (Chelton et al., 2004; Sørensen, 2007b), and the area fractions of nearshore waters employed are similar to those already set aside for wind power purposes in Danish waters. Biomass potentials are estimated from global vegetation growth models (Melillo et al., 1993; Sørensen, 2004). The hydro figures are the current actual production (NORDEL, 2005), as no expansion is foreseen, and finally, the solar radiation and collector model used for Germany is described in Sørensen (2004). It assumes photovoltaic collectors with an average efficiency of 14\% 
to be installed on about a quarter of all suitable south-facing building roofs and upper facades, but with removal of useful thermal heat from the same collectors at an average efficiency of $36 \%$. The combined heat and power panels are denoted "PVT collectors".

\section{ENERGY CONVERSION, STORAGE AND TRANSMISSION}

Because of the likely high proportion of electricity in the primary energy mix of the scenarios to be constructed, as caused by the large identified resources involving wind and hydro in the countries modelled, it is envisaged that electricity will cover not only demands specifically requiring this form of energy (called "dedicated electricity"), but also other demands such as industrial process heat, space heating and hot water needs in private and commercial buildings. This requires energy conversion, which is assumed to be by use of electric furnaces for high-temperature heat and use of heat pumps for low-temperature heat, taking advantage of a high COP of 3 to 4.5 (the coefficient of performance, COP, is the energy ratio of heat output to electricity input). Due to the intermittency of wind power, also conversion to and from a storable energy form is considered, although a competing option might be to use power import and export to cope with fluctuations, provided that there are surpluses or unsatisfied demands in the neighbouring system, whenever the need for import or export arises.

There is clearly a strong dependence of these issues on the precise nature of the wind variability. The time-series shown in the adjacent article (Sørensen, 2007a) indicate that seasonal variations on average are similar to those of demand, and that deficits are compensated by later surpluses on a time scale of a few weeks. This is then the required storage period, if storage is used to cope with the intermittency. Another way to view the variability of wind is to construct power output duration curves, showing how large a percentage of time the power exceeds a given value. For a single wind turbine erected in a given climatic regime, there is usually a fraction of time (typically 20-30\%, cf. Sørensen, 2004) where no power is generated. For the combined production of a geographical region there is a smoothing effect of the wind variability over the distance of turbine dispersal. For a small-size country such as Denmark (some $500 \mathrm{~km}$ width) this leads to power curves such as the ones shown in Figure 6, representing all on-shore or all off-shore sites. It is seen that now there is always some output, but it goes to zero when availability all hours of the year is required. The maximum output, on the other hand, is around twice the average. The precise value depends strongly on turbine construction (blade profiles and procedures for handling high-wind situations, e.g. by shutting down the turbine above say $25 \mathrm{~m} / \mathrm{s}$ winds, cf. Sørensen, 2004).

In Figure 7, power duration curves for off-shore wind power production are shown for all five countries studied. As expected, the German duration curve is very similar to the Danish one, because German coastlines are all in the North (facing Baltic Sea and North Sea). The Norwegian duration curve is quite different, with many more hours of high output. In fact, $20 \%$ of the average power is available more than $99 \%$ of the year, $50 \%$ of the average power is available $95 \%$ of the year. The reason is of course that there is excellent wind production potential all along the Norwegian West-coast, covering a latitude span from $58^{\circ} \mathrm{N}$ to $71^{\circ} \mathrm{N}$ or some $1500 \mathrm{~km}$. This means that climatic differences in circulation patterns are large enough to produce substantially different wind regimes in the North and in the South, and hence smoothing of combined turbine power output. Typical sizes of weather front systems is of the order of $500 \mathrm{~km}$ (see e.g. Sørensen, 2004). For Sweden and Finland, the situation is intermediate between that of Norway and Denmark. Although the distance between Northern and Southern parts of these countries is also large, the wind conditions are favourable only on exposed coasts facing the Baltic Sea to the West or the South, and for Sweden the small coastline towards the Kattegat and Skagerak North Sea inlets. The 
interesting implication of these features is, that if the energy systems of these countries use high proportions of wind power, both for some non-time-urgent tasks such as hydrogen production and for direct coverage of power needs, then the fraction of dedicated electricity use may be low enough that is can be covered at all times, even without energy storage and with power trade only inside the region.

Biomass harvests often take place at specific times during the year, although collection of forest management wastes is more flexible. However, it is considered that the biomass residues used in the scenarios can either themselves be stored, or the biofuels obtained after conversion can. All the conversions lead to fuels (liquid fuels such as ethanol, methanol and biodiesels or gaseous fuels such as methane or hydrogen) that are storable in ways similar to present oil and natural gas storage. The reason for accepting a loss of around $50 \%$ of the energy by conversion to fuels is the specific needs of the transportation sector, together with the obvious lack of need for more electricity than can be derived from wind and hydro resources in the region, in all the countries considered except possibly Germany (see below). Any heat demand can be covered either by the losses in conversion, in those cases where district heating lines are available from the earlier non-renewable energy system (Germany, Denmark and Southern Sweden and Finland), or by heat pumps using the excessively available electricity, in cases where heat of fairly low temperature is required. Hightemperature heat may be created by electric furnaces (based on wind if available or hydro) or by biomass furnaces (and in these case without much energy loss).

One alternative to biofuels in the transportation sector is fuels generated from electricity, of which hydrogen (by alkaline or proton-moving membrane fuel cell (PEM) electrolysis) is a clear possibility, having conversion losses expected to become lower than the current $20-30 \%$ (for large installations) and possibly as low as 5\% (Sørensen, 2005). A further alternative is to use electric vehicles based on batteries, with a round-trip efficiency of around $75 \%$ but a serious weight penalty (lead or metal hydride batteries) and/or cost penalty (lithium-ion batteries). Most likely, pure electric battery-vehicles will only be serving special markets (such as city delivery and public transport), while battery-biofuel or battery-fuel cell hybrid vehicles offer quite attractive compromises between weight and cost. They will require environmental attention, primarily in terms of particle and $\mathrm{NO}_{\mathrm{x}}$ emission control devices (Sørensen, 2006a, 2006b).

The energy storage options considered for handling the intermittency of particularly wind energy are hydro reservoir water storage and geological storage of hydrogen or other compressed gases (such as air). Hydro stores are abundant in the Northern countries, with reservoirs allowing seasonal smoothing of power generation. Peak water-inflow is in early summer, when snow covering the catch areas melts. Reservoir fillings have been monitored over several decades and show important variations between years, in addition to the seasonal behaviour illustrated in Figure 8. The inflow is derived from historical data (NORDEL, 2005) by adding power production to the signed increase in reservoir filling (translated into energy units).

The Nordic countries are characterised by generous access to renewable energy: Large amounts of hydropower in Norway and Sweden, large amounts of wood scrap from forestry operations in Sweden and Finland (to be converted to e.g. methanol in the scenarios) and large amounts of wind energy along coastal sites in all of the four countries (plus the $5^{\text {th }}$ Nordic country, Iceland, which is not included here because it has no grid connections to the other countries). It is therefore not surprising, that the simulations show that these countries can be self-sufficient in energy supply from such renewable sources. The intermittency of wind energy turns out not to be so large, that any substantial trade of electric power between the Nordic countries is called for. The reasons are first the difference in wind regimes discussed in connection with Figure 7, and second the establishment of a level of wind exploitation considerably greater that that required by dedicated 
electricity demands. The latter choice implies that a part of the wind power generated does not have time-urgent uses but may be converted (e.g. to hydrogen) at variable rates, leaving a baseproduction of wind power sufficient to cover the time-urgent demands.

In Figure 9, the on- and off-shore wind power production of each country is shown, relative to the total land area of the country. Measured in this way, Denmark has the highest wind potential. Representing the totals relative to the country's population, the situation is as shown in Figure 10a. This is a relevant indication, as power usage is roughly proportional to population size. It is now seen, that Norway has a very large wind resource, the three other Nordic countries a substantial resource, but Germany only a very modest one. Except for Germany, the highest potential is offshore, even if the placement of wind turbines is limited to the off-shore fraction of grid squares with an size of something like $25 \mathrm{~km} \times 50 \mathrm{~km}$ (cf. the discussion in Sørensen, 2007a). The exploitation of potential wind sites inland is very modest, assuming that the area swept by turbine rotors is only $0.01 \%$ of the land area for all countries except Denmark, where it is $0.02 \%$. Due to the fairly large grid size used, a large number of mixed grid land-sea cells in Denmark are classified as off-shore (the criterion used is a water fraction above 20\%, cf. Fig. 13 in Sørensen, 2007a). Including the onshore fraction of these, the Danish on-shore average wind production becomes 2027 MW, a reasonable estimate corresponding to the use of only sites already having a wind turbine today, but replacing the smaller turbines with units of at least $2 \mathrm{MW}$. The current average Danish production is about $830 \mathrm{MW}$. The larger turbines will have different production profiles (cf. Figure 9, top) from today's, because of the larger hub height and presumably modified power curve. The power curve assumed for all turbines in the current study is shown in Figure 10b.

For off-shore grid cells considered for wind power production, the turbine swept area is for all countries taken as equal to $0.01 \%$ of the (horizontal) grid-cell area. For mixed on- and off-shore grid cells, the water- and non-water fractions are used to assign wind production. It is interesting to note (see Figure 9, top), that the selected turbine characteristics imply a peak shaving in high-wind situations for Denmark that is absent in e.g. Norway. The reason for this behaviour of the total onland production of each country is that Denmark is small enough to have fairly homogeneous highwind episodes (exhibiting peak-shaving), while for Norway, the wind regime differences between North and South is large enough to conceal the peak shaving of one fraction having high winds, because there will be other regions without high winds during the particular hour looked at. The estimated off-shore production potential for Denmark (Figure 9, bottom, and Figure 10a, top) agrees well with estimates of the potential power production from areas already set aside for off-shore wind parks (cf. Danish Power Utilities, 1997; Sørensen, 2005, p. 325).

Transmission costs will necessarily be larger in a future system using all the above-mentioned options. Partly, there is increased transmission between regions (or countries), if trade is used to handle supply-demand mismatch, and between stores and load-centres, if energy storage is taking over the intermittency handling, and partly there is additional transmission between the new power production locations (such as off-shore wind parks) and the locations of electricity uses (including the sites of conversion facilities for hydrogen production, whether done centrally or decentralised). Although quite substantial, these costs are still a minor fraction of the total costs of the proposed energy system (Sørensen, 2004).

\section{SIMULATION METHOD}

A number of one-year time simulations were made for possible future energy systems combining the data series (using a 6 hour time step) for supply and demand as discussed above, and with use of 
different sets of conversion devices with different orders of priority. The simulation year is taken as 2060 in order to be able to assume that the present system has been largely phased out in an orderly fashion, i.e. without premature retiring of equipment. One set of simulations assumes half the transportation activities to use fuel cell-battery hybrid vehicles and the other half Diesel or Otto engines in vehicles of high basic efficiency. Hydrogen is stored in underground caverns such as aquifers or salt dome intrusions and piped to filling stations (Sørensen, 2005; 2006). Power transmission lines within and between the countries are assumed upgraded as necessary. Biofuels can be used at arbitrary pace, while solar and wind energy must be used or converted as produced.

The energy form initially produced is either electricity, liquid fuels or heat. A priority schedule then first allocates bound or available production to simultaneous demands, then consider using stored energy for unsatisfied demands and finally consider energy transformation from one form to another, so that additional demands may be covered. Hydropower in the Nordic countries is reservoir-based and can be regulated. For this reason, it is given second priority after wind and photovoltaics for covering time-urgent loads. Heat is divided into low-temperature (under $90^{\circ} \mathrm{C}$ ) and high-temperature (over $90^{\circ} \mathrm{C}$ ) heat, the latter being supplied by converting electricity or fuels and the former by associated heat from power-producing fuel cells or other power plants or boilers, and else by heat pumps using electric power at a coefficient of performance around 4 (using soil or water streams as low-temperature reservoirs). Hydrogen is produced by fuel cells in reverse mode of operation, or by electrolysers (which are also fuels cells, but of alkali type as opposed to the membrane types currently appearing most promising for automotive purposes).

A separate set of simulations have been made, assuming that viable fuel cells will not become available, putting more strain on the biofuels for use in the transportation sector. Hydrogen can still be used for storage, but due to the large amounts of hydropower based on seasonal reservoirs in the region, this turns out to be unnecessary in the Nordic countries.

The simulations are first performed for each country alone, identifying export potentials and import requirements, both in the form of a time series. A second round of simulations is then performed, using the identified surpluses as import options for those countries with unsatisfied demands. In some cases this involves choosing between different options for trade between the countries.

\section{SIMULATION RESULTS FOR EACH COUNTRY IN ISOLATION}

Figures 11-15 show some uses of electric power produced in the countries involved, for a scenario with use of fuel cells and geological hydrogen storage, but before considering trade between the countries. Because all the identified renewable energy sources are assumed exploited, there is a large surplus of energy in the Nordic countries, making them able to benefit from an important export trade of both power and fuels to the European continent, should they elect to do so.

Except for Germany, the number of hours where wind cannot cover the direct electricity demand is quite low. The same is true for coverage of heat demands by electric furnaces (high-temperature heat) and by heat pumps (low-temperature heat). The hours of deficit are in all cases covered by conventional combined heat and power plants or, as a secondary priority, separate power and heat plants using biofuels. The availability of biofuels (associated with residues from a large agricultural sector in Denmark and Germany, and residues mainly from forestry in the other three countries, supplemented by aquaculture if necessary) allows all needs in the transportation sector to be covered. Alternatively, hydrogen may be generated from excess wind (and here the occasional deficits do not matter, since hydrogen may be stored in the underground caverns) and used in the 
transportation sector, leaving more biofuels to be exported to countries with less abundant renewable energy supply. For Denmark, this is shown in the lower part of Figure 11. All the Nordic countries have large amounts of wind power and biofuels potentially available for export. The scenario initially assumes that half of the energy for transportation is assumed derived from hydrogen, and Figures 16 and 17 show the role of a moderate size store placed in Denmark and Finland, respectively, each with an assumed capacity of $1.37 \mathrm{PJ}$, which is quite modest. In Denmark, the hydrogen store is capable of smoothing the wind power deficits during the months of March and April, while in Finland, hardly any smoothing is required. For the remaining Nordic countries, the situation is as in Finland. The role of the hydrogen store is thus basically to insure against unusually long periods without wind energy for producing hydrogen for vehicles. Hydrogen production from biomass is not included in the present scenarios.

Sweden, Finland and particularly Norway have a large electricity production based on (already existing) hydro. Figure 18 shows the build-up of a large exportable potential power export from Norway during the simulation year, due in part to the high wind power production coupled with the priority given to wind turbines (once built) in covering supply. The curves for Sweden and Finland are similar, although the total export potential is smaller, especially for Finland.

The situation for Germany is particularly interesting, as the renewable resources are here considerably more modest than for the Nordic countries: very little hydro, suitable wind power locations only at the northern coasts (Baltic and North Sea), and some solar energy derivable from building-integrated panels. Biofuels are more abundant, based primarily on residues from a sizeable agricultural sector, and there are some forestry residues, while aquaculture is limited by the small coastline (although inland waterways may be used to some extent). Figure 15 indicated the need for generating more electricity than can be provided by hydro, wind and photovoltaic power, and tentatively attributed this to conversion from biomass. However, the required amount of biomass makes the total amount of biofuels available within Germany insufficient for also covering the needs of the transportation sector, and in section 5 below follows a discussion of different import options for covering this German deficit in meeting demand with indigenous renewable resources.

It was from the start clear that it would be difficult to secure enough renewable energy for a German population more than four times as large as that of the Nordic countries combined, on a land area considerably smaller. Yet, the simulation behind this section's results shows that for the given choice of priorities in assigning coverage, demand for electricity and heat for both space conditioning and processes can indeed be covered, but as stated then only a part of the demand for transportation energy.

Figures 19-21 show the disposition of hydrogen and biofuels for Denmark, Norway and Germany. Sweden and Finland is similar to Norway. The Nordic countries satisfy $50 \%$ of their transportation needs by hydrogen used in fuel cell vehicles (probably as hydrogen-battery hybrids) and the other $50 \%$ by biofuels. There is scope for changing the relative contributions, e.g. if fuel cell costs do not come down sufficiently or if the environmental effects remaining in combustion of biofuels are not accepted by future societies. Denmark has to use a small amount of biofuels for industrial process heat, while the other Nordic countries can do with electric furnaces based on wind and hydro. For Germany, it is not possible to satisfy the transportation sector needs by indigenous energy resources, and the isolated country scenario lumps the deficit as a need for fuel imports. In this case, as seen in Figure 21, there is not sufficient wind-based hydrogen to supply $50 \%$ of the transportation energy.

The 2060 scenarios cover low-temperature heat (such as for space heating, hot water and industry) by a combination of excess heat from energy conversions (e.g. in fuel cells), assumed to be 
distributed through existing district heating lines, locally produced heat produced from environmental heat and electric power in heat pumps, and if any further demand exists then by direct combustion of biofuels. The situation is similar in the countries looked at, so only the Danish low-temperature heat provision is illustrated, in Figure 22.

In Figures 23-26, the surpluses available for export from the Nordic countries are shown. A large potential export of as well biofuels, intermittent wind power or hydro energy is available. Figure 27 sees these as import options for Germany, which needs to import energy.

The additional potential for energy exports from the Nordic countries may go to other continental European countries, e.g. via the transmission lines to Germany, or alternatively, the expansion of renewable energy production equipment may be halted at a lower level. The potential export amounts shown in Figures 23-27, particularly for electric power, are so large that extended transmission over larger distances may appear too costly. For biofuels, the large export potential may be reduced, either if the cost of converting not grains and sugar but residues to fuels appear too high, or for sustainability reasons, if future farming becomes entirely ecological and if the recycling of nutrients to the fields turn out to be more difficult than anticipated. In this connection, the energy requirements for transportation of residues from and back to the fields, forests or aquaculture locations are important factors influencing the decision (as well as the location of biofuel conversion facilities, cf. Sørensen, 2004).

\section{SIMULATION RESULTS WITH ENERGY TRADE BETWEEN COUNTRIES}

Having established the large energy export potentials of the Nordic countries and the substantial import need of Germany, a second set of simulations were performed, putting the Nordic surpluses or some of them at the disposal of the German energy system and rerunning the German model with these available import options given in terms of time series of electric power or biofuels offered.

The outcome is illustrated in Figures 28-31. Figure 28 shows the new optimisation of power and fuel disposition in the presence of the new import options. The lower part of Figure 28 shows how production of hydrogen based on imported (and intermittent) power is taking a decisive role in covering the demands both in the transportation sector and for some of the heat and dedicated electricity demands (Figures 29 and 30). As a consequence, the use of biofuels in conventional power and heat plants is diminished, and there is an apparent sequence of periods with sufficient German biomass and periods with import needs (Figure 31). However, as biofuels can be stored, the net result is self-sufficiency in fuels. That electricity is imported rather than biofuels is a result of the priorities built into the model, where uncontrollable energy production from already installed capacity has preference over controllable production. The average electricity surplus from the Nordic countries combined is some $2700 \mathrm{PJ} / \mathrm{y}$, and it is seen that Germany needs to import nearly all of this to achieve the hydrogen production required. An implication of this is a reinforcement of power transmission lines several places in the system, but still entailing an expense considerably lower than that of establishing a hydrogen pipeline system to accomplish the same level of trade.

\section{ALTERNATIVE SCENARIOS AND DISCUSSION}

Provided that the development of biomass-to-biofuel conversion technologies is successful and allows the full potential identified here to be exploited at a reasonable cost (compared to the 
hydrogen/fuel cell alternative) and without unacceptable environmental impacts, then one may shift the priorities and cover the German deficit by imported biofuels rather than imported electricity. Transport of biofuels is less costly than power transmission and there is no intermittency that increases the cost of further conversion because the installed conversion capacity cannot be used at all times. Figure 32-35 shows the results of an alternative simulation run for Germany, with only biofuel imports. These fuels now take over many of the roles attributed to hydrogen in Figures 2831. Electricity deficits are covered by combined heat and power plants (Figure 32). They are assumed fuelled by biofuels rather than by raw biomass (such as straw or wood scrap), because biofuels have considerably higher energy densities and hence lower transport costs. However, if these cost gains are not considered capable of off-setting the conversion losses associated with the biomass-to-biofuel conversion (some 50\%), German imports could be of raw biomass residues. Figure 33 shows the reduction in use of electricity (compared to Figure 28 bottom panel) when no electricity import options are available. The coverage of low-temperature heat is shown in Figure 34, and Figure 35 indicates the total requirement for biofuel imports in the fuel-import only scenario.

Several other scenario variants have been subjected to simulation. One assumed that Norway does not develop its wind potential. Reasons could be that the delicate placement of turbines along the Western shoreline would meet with economic or environmental resistance. Economic problems could arise from the fact that rapidly increasing water depths could make the foundation work for the wind turbines too expensive, forcing the turbines closer to the shore or up on the rock-covered islands and shores. This could lead to lack of acceptance for reasons of disturbing the visual environment. The objection is less convincing than the strong protests launched earlier against the establishment of hydro reservoirs, because while the latter constitute irreversible changes of the ecosystems involved, a wind turbine can be removed at any time, leaving the ecosystem and visual environment exactly as before the turbine was built. Further reasons for perhaps not seeing the Norwegians use their exceptional wind potential could be the transmission costs from turbines to load centres, which would in many cases have to cross difficult terrain and probably require avoidance of overhead lines, again for visual environmental reasons. In any case, the result of not expanding Norwegian wind is negative only for Germany, which (in the scenario behind Figure 31) would have to import more biofuels to make up for the missing electric power. As shown above, there is scope for avoiding all power imports, but most likely, the import of electricity from the countries already electrically connected with Germany (i.e. Denmark and Sweden) would be seen as beneficially, at least in the event that fuel cell technology becomes viable for the transportation sector.

In summary, it has been shown that a high level of renewable energy exploitation could provide substantial economic benefits for endowed countries such as the Nordic ones, as well as stable energy supply benefits for deficit countries like Germany, and that additionally, the storage/backup problem associated with the intermittency of wind and solar energy will actually be diminished by a higher level of exploitation, particularly if it stretches as far, geographically, as from Germany to North Cape. 


\section{REFERENCES}

Bockris, J. (1972). A hydrogen economy. Science 179,1323.

Chelton, D., Schlax, M., Freilich, M., Milliff, R. (2004). Satellite measurements reveal persistent small-scale features in ocean winds. Science 303, 978-983.

Danish Power Utilities (1997). Action plan for off-shore wind parks, SEAS Wind Department (in Danish).

Kalnay, E., et al. (1996). The NCEP/NCAR 40-year reanalysis project. Bull. Am. Met. Soc. (March issue).

Marchetti, C. (1973). Chem. Econ \& Eng. Review 5, 7.

Melillo, J., McGuire, A., Kicklighter, D., Moore-III, B., Vorosmarty, C., Schloss, A. (1993). Global climate change and terrestrial net primary production. Nature $363,234-240$.

Nielsen, S., Sørensen, B. (1998). A fair-market scenario for the European Energy System. In "Long-term integration of renewable energy sources into the European energy system” (LTI-group, ed.), pp. 127-186. Springer-Physica Verlag, Heidelberg.

NORDEL (2005). Spreadsheet data report no. 2005-00537-01, supplement to Annual Report 2005, no. 2005-00336-01. Nordic Power Utilities Association.

Sørensen, B. (1975). Energy and resources. Science 189, 255-260.

Sørensen, B. (2004). Renewable Energy, 3rd edition, Elsevier Academic Press, Boston, 946 pp.

Sørensen, B. (2005). Hydrogen and fuel cells. Elsevier Academic Press, Boston, 465 pp.

Sørensen, B. (2006a). On the road performance simulation of hydrogen and hybrid cars. Int. J. Hydrogen Energy, doi: 10.1016/j.ijhydene.2006.06.069.

Sørensen, B. (2006b). Assessing current vehicle performance and simulating the performance of hydrogen and hybrid cars. Int. J. Hydrogen Energy, doi: 10.1016/j.ijhydene.2006.10.037

Sørensen, B. (2007a). A sustainable energy future: Construction of demand and renewable energy supply scenarios. Int. J. Energy Resrarch (this issue).

Sørensen, B. (2007b). Estimating off-shore wind potential from satellite scatterometer data (in preparation).

Sørensen, B., Meibom, P. (2000). A global renewable energy scenario. Int. J. Global Energy Issues, 13, 196-276.

Sørensen, B., Meibom, P., Karlsson, K., Nielsen, L., Petersen, A. and Lindboe, H. (2007). Comparative assessment of hydrogen storage and international electricity trade for a Danish energy system with wind power and hydrogen/fuel cell technologies. Energy Research Programme of the Danish Energy Agency 2005-7. Report in progress.

Veziroglu, T. (1975). A universal hydrogen energy system and world parameters. Proceedings of a symposium on introduction to hydrogen energy. Marcay, Venezuela. 


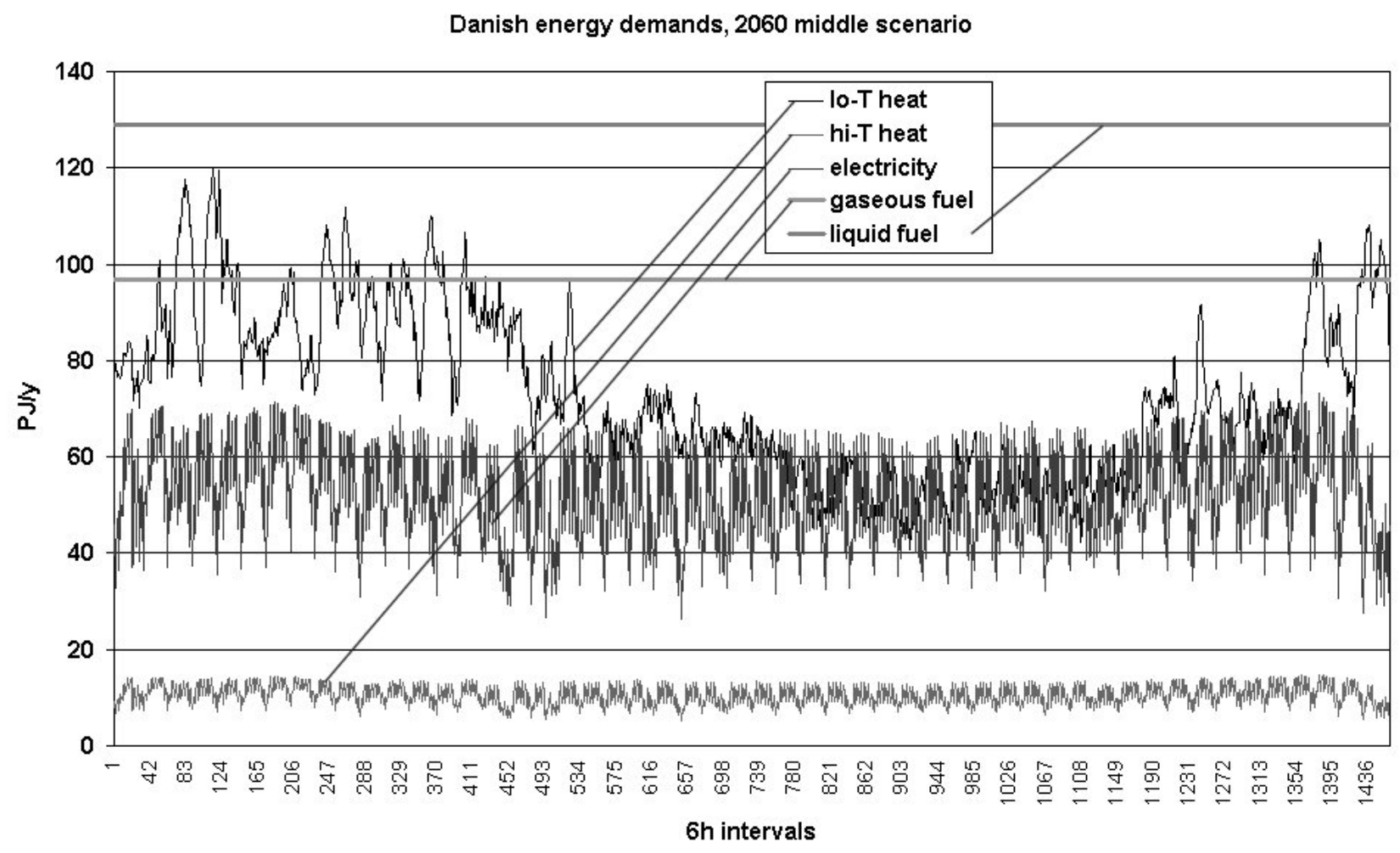

Figure 1. Energy demands for Denmark used in the 2060 scenario. The electricity usage shown is dedicated electricity, implying that further electricity may also be used to cover other needs, if convenient. The energy delivered for transportation is divided equally between fuel cell vehicles using hydrogen ("gaseous fuel”) and biofuel vehicles (using "liquid fuel” such as biodiesel, ethanol or methanol), but the demand is different due to different engine efficiencies.

Norwegian energy demands, 2060 middle scenario

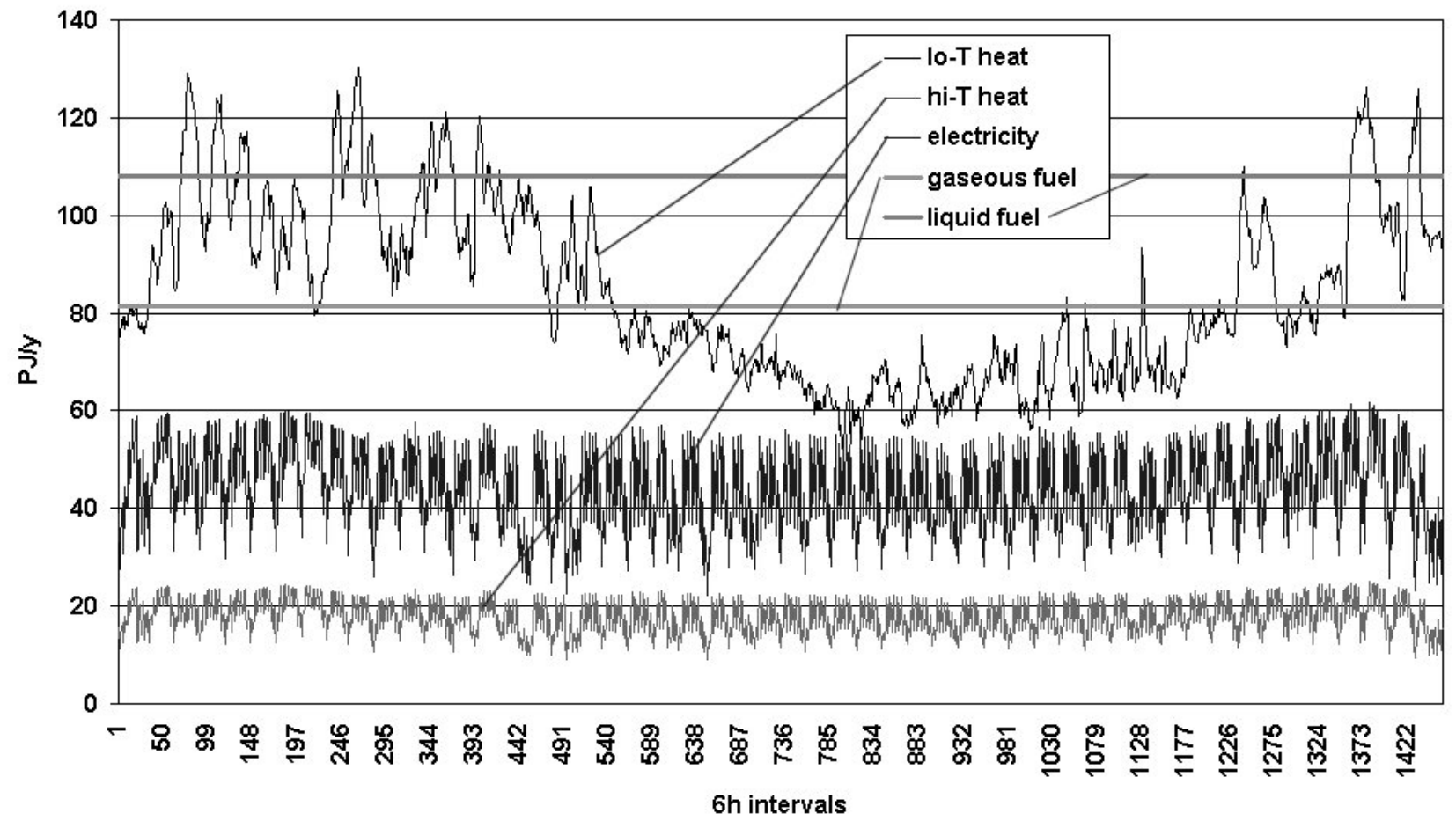

Figure 2. Energy demands for Norway used in the 2060 scenario. See remarks in caption to Figure 1. 


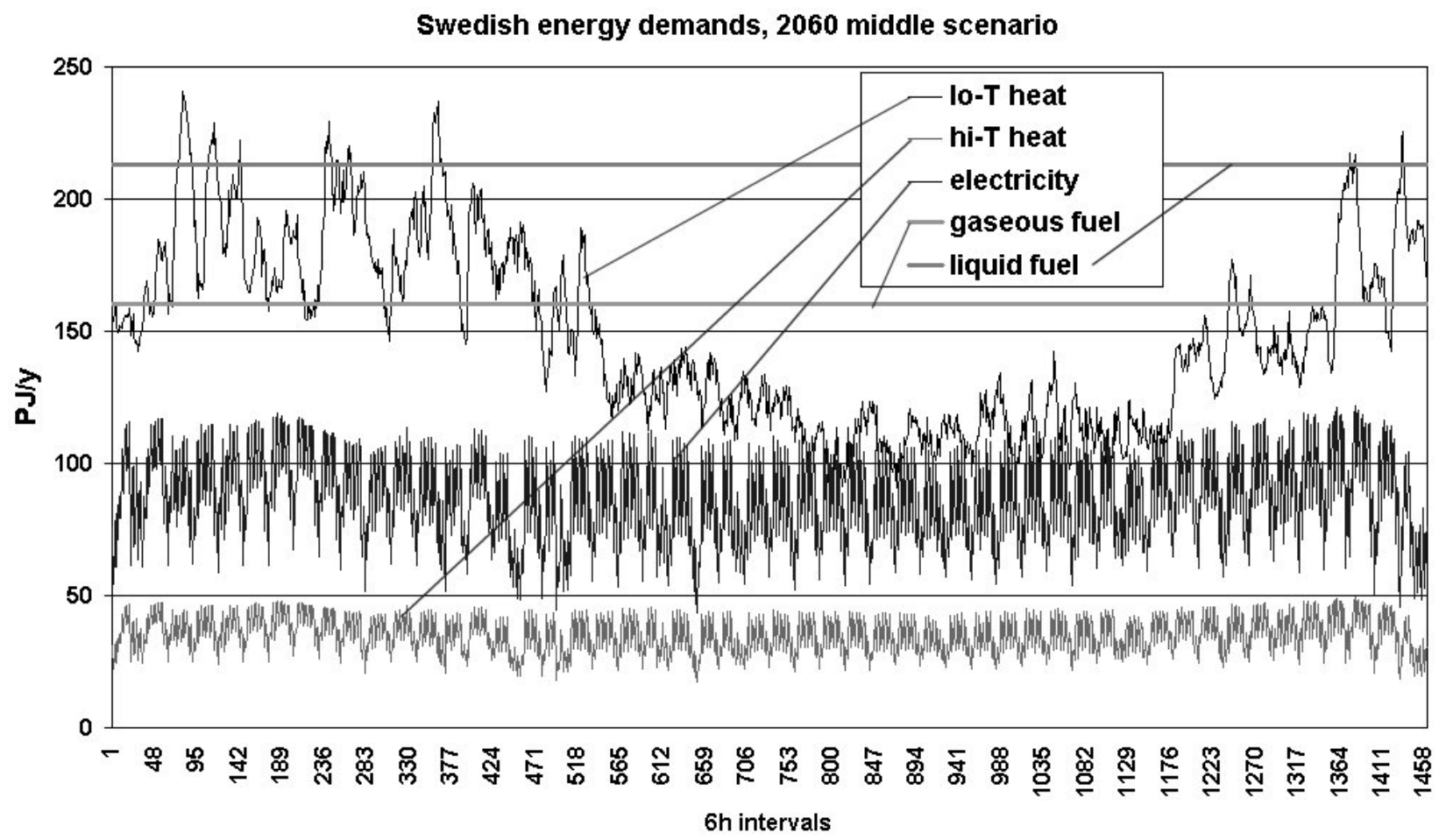

Figure 3. Energy demands for Sweden used in the 2060 scenario. See remarks in caption to Figure 1.

Finnish energy demands, 2060 middle scenario

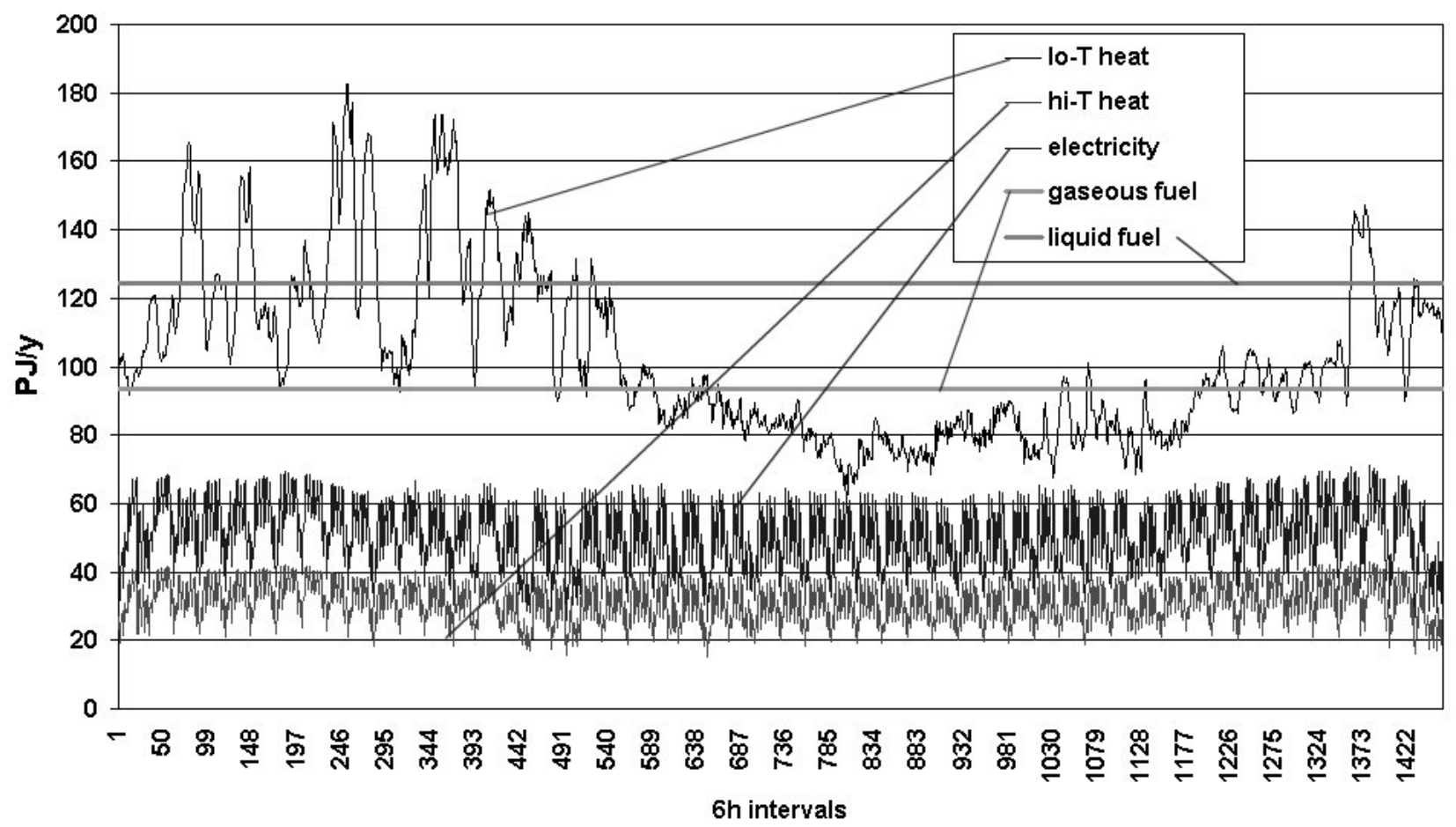

Figure 4. Energy demands for Finland used in the 2060 scenario. See remarks in caption to Figure 1. 


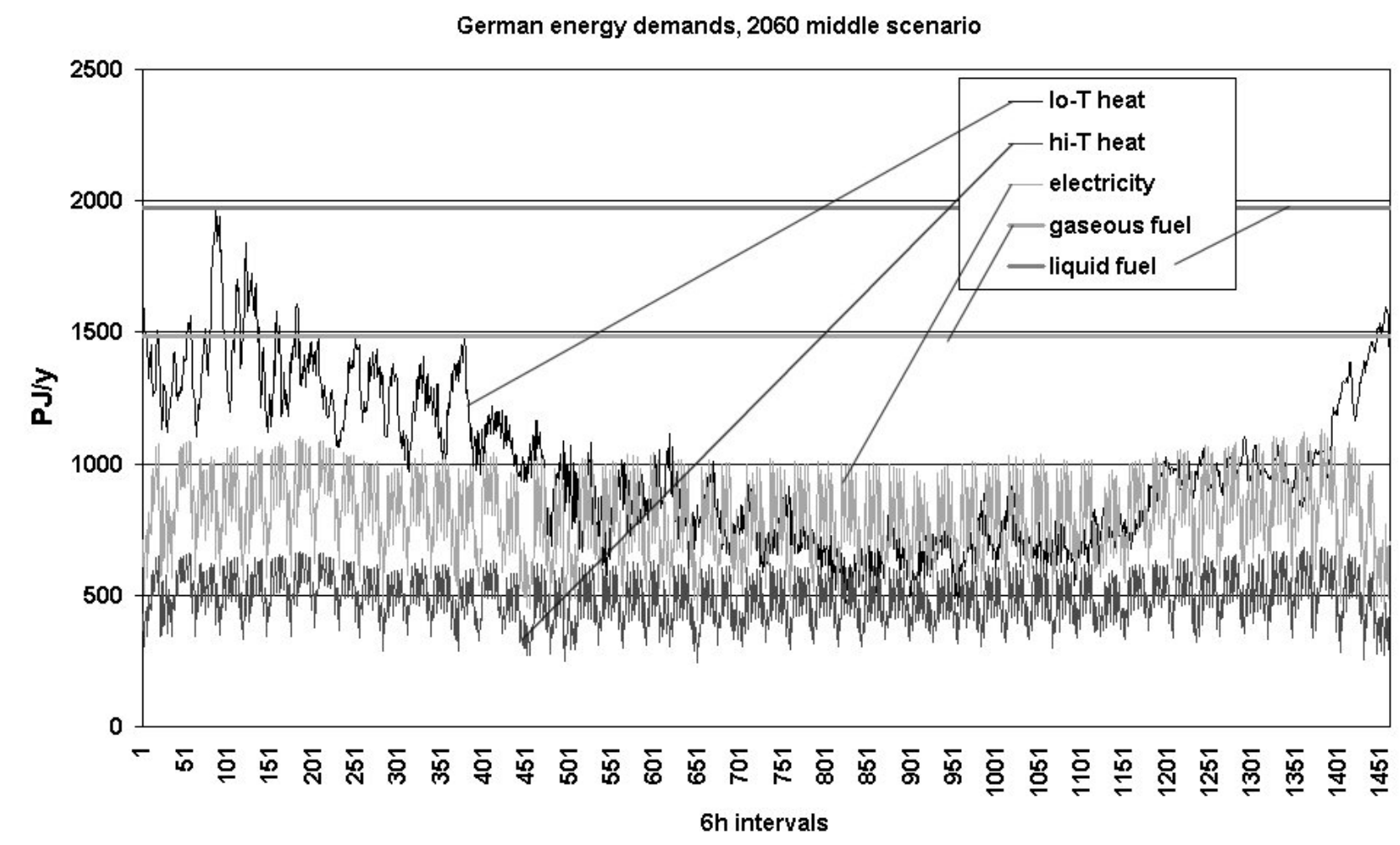

Figure 5. Energy demands for Germany used in the 2060 scenario. See remarks in caption to Figure 1.

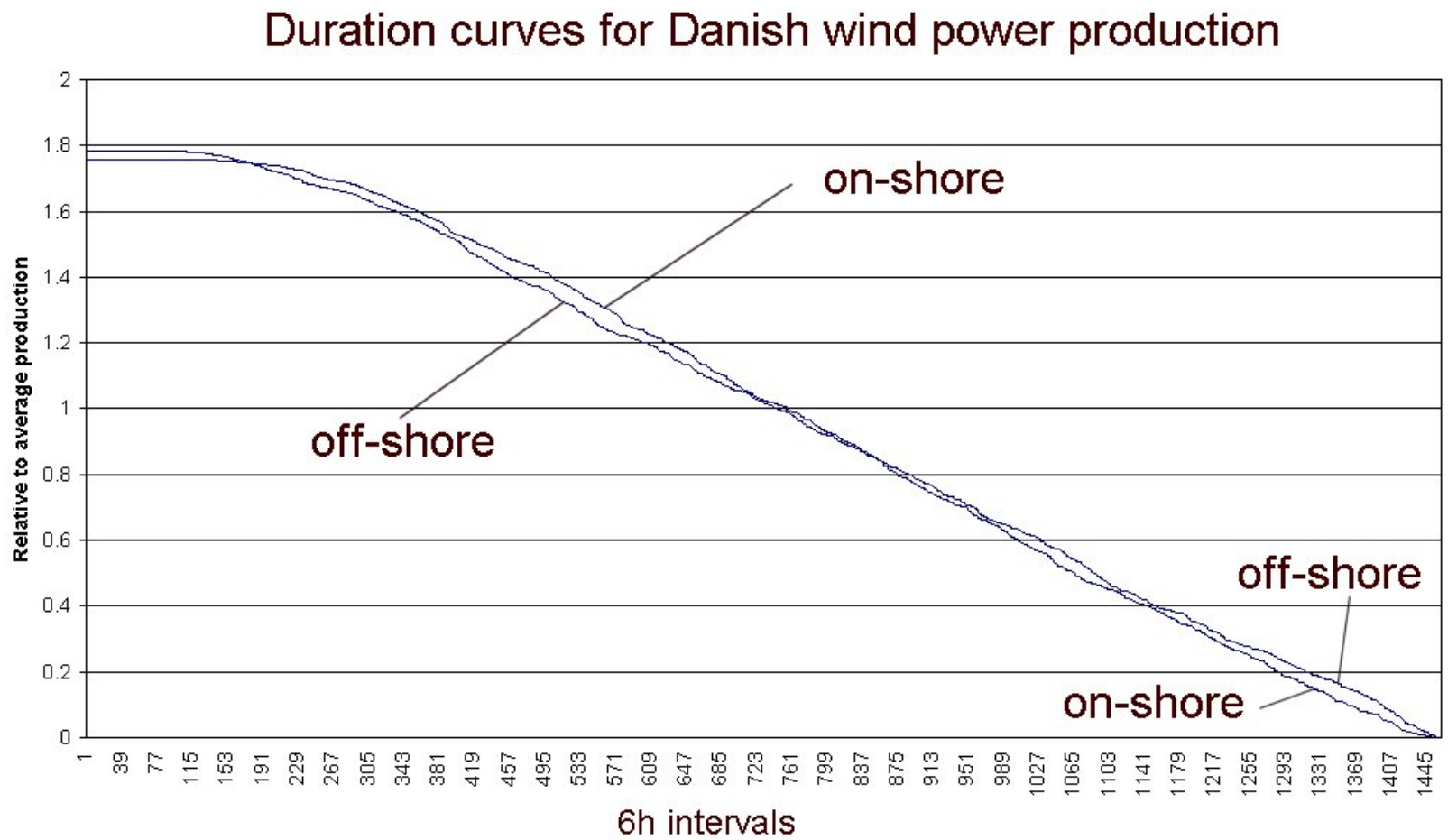

Figure 6. Power duration curves for Danish power output of all on-shore and all off-shore wind turbines considered in the scenarios. The off-shore wind production is only slightly more persistent than that on land, for the identical turbine power curves (power output as function of wind speed, see Figure 10b) assumed for the 2060 technology. This is in contrast to the current situation, where use of annual-production optimised turbines on land but not off-shore reduces the number of production hours for land-based turbines and in return gives a maximum production of more three times the average (cf. Sørensen, 2004). 


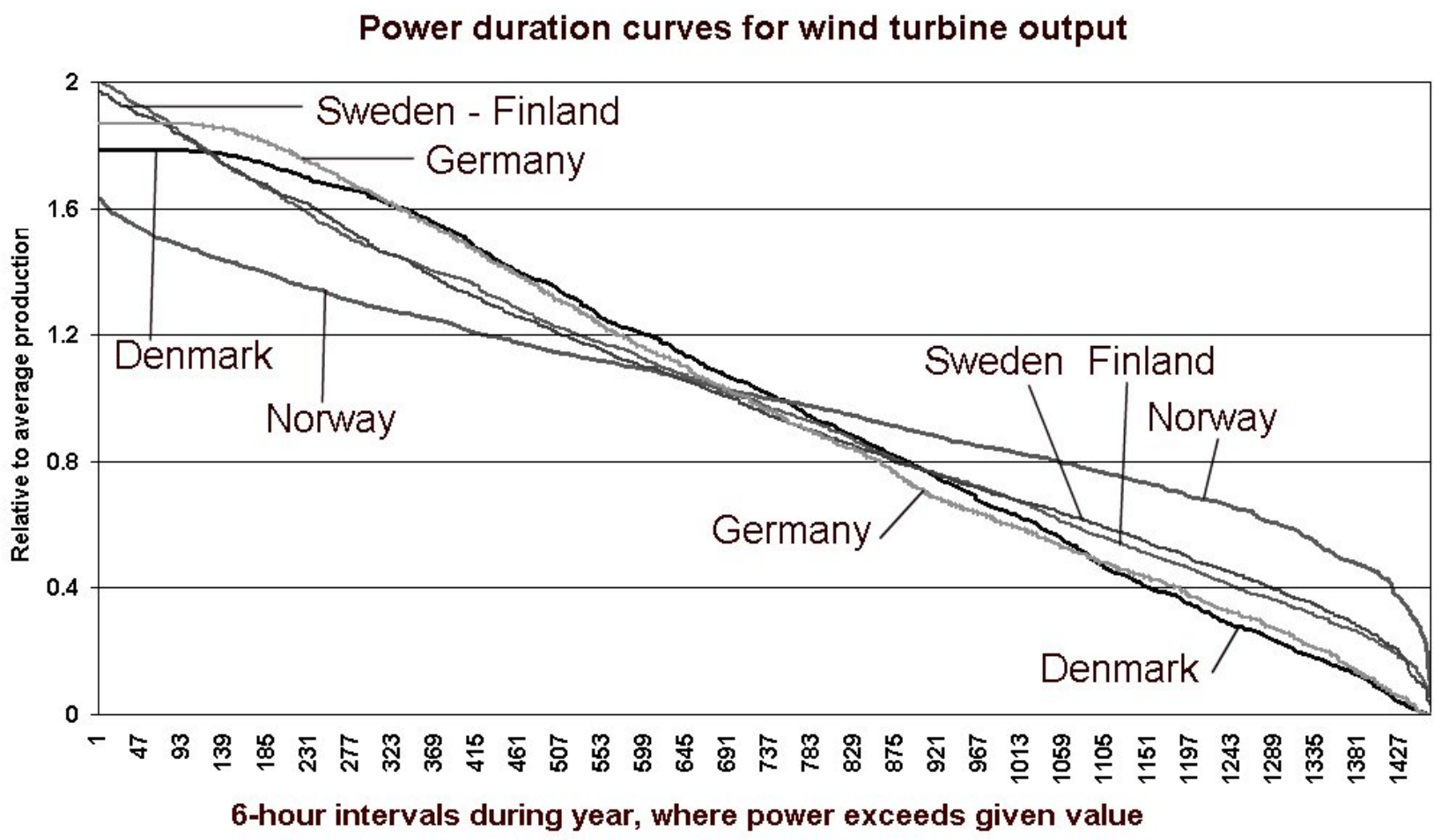

Figure 7. Power output duration curves for all off-shore wind turbines in the 2060 scenarios of the five countries studied. See text for a discussion of differences between the curves. 

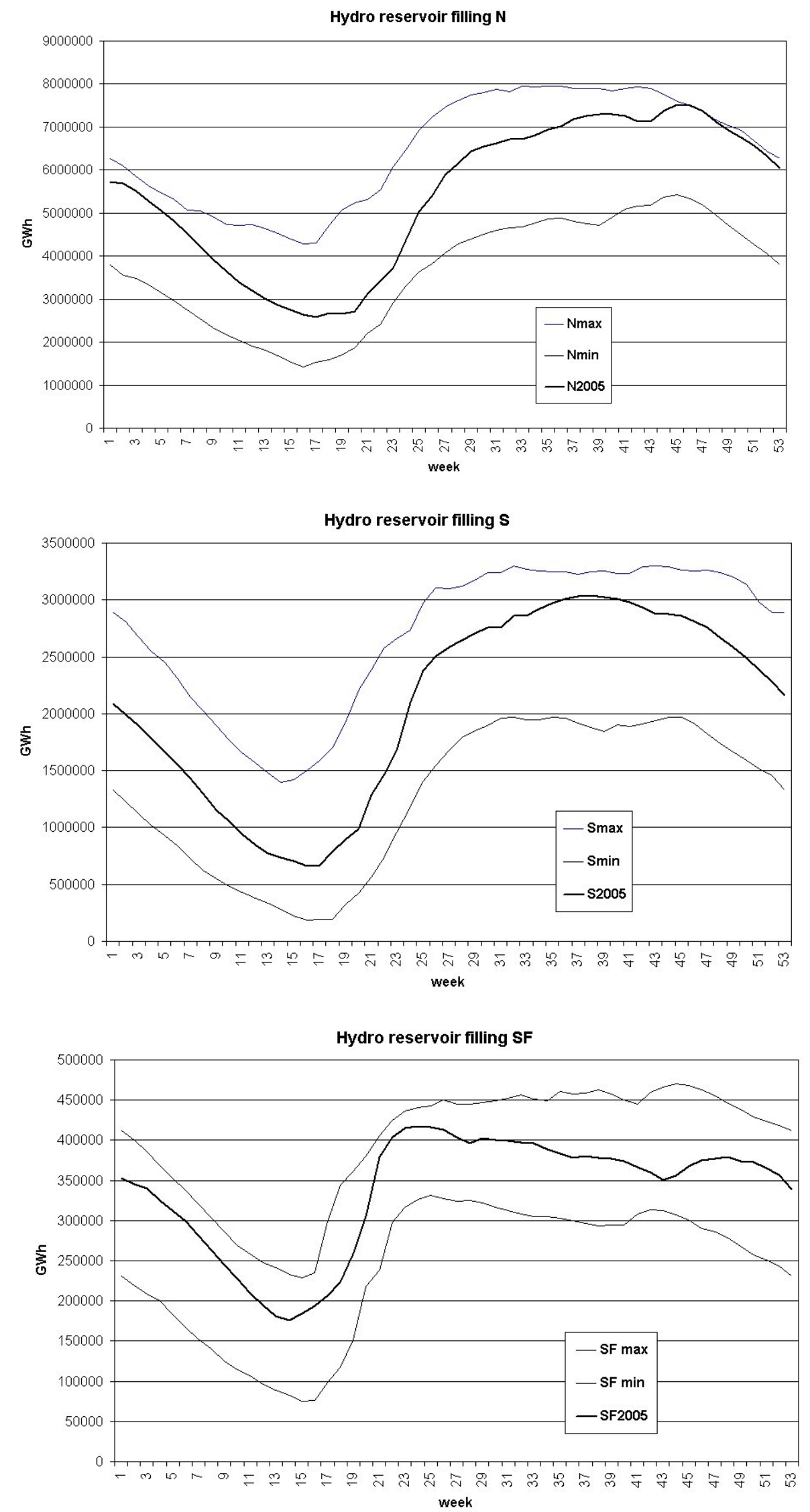

Figure 8. Current filling of Nordic hydro reservoirs, through the year 2005 and indicating the minimum and maximum filling for each week in the wear, over the past decades. Based on data from NORDEL (2005). 


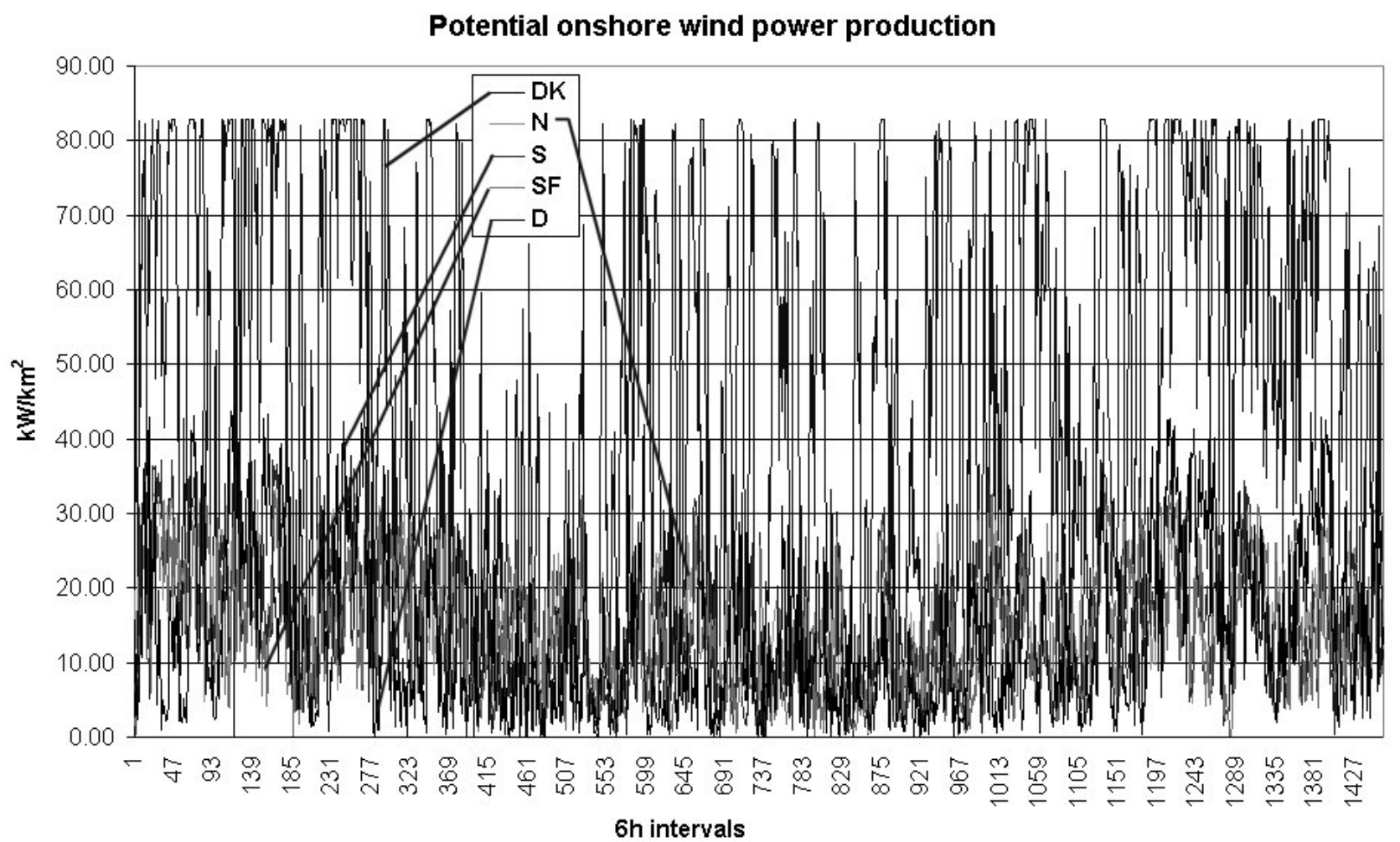

Figure 9. Wind power production from the sites selected for suitability, environmental acceptance and non-conflict with other area uses, in the countries studied. The unit $\mathrm{kW} / \mathrm{km}^{2}$ is total power production divided by the country's total land area (i.e. not just the areas with wind turbines). The total production on land areas are shown above and the total production off-shore is depicted below. The off-shore locations are near-shore, as shown in Fig. 11 of the adjacent article (Sørensen, 2007a).

Potential off-shore wind power production

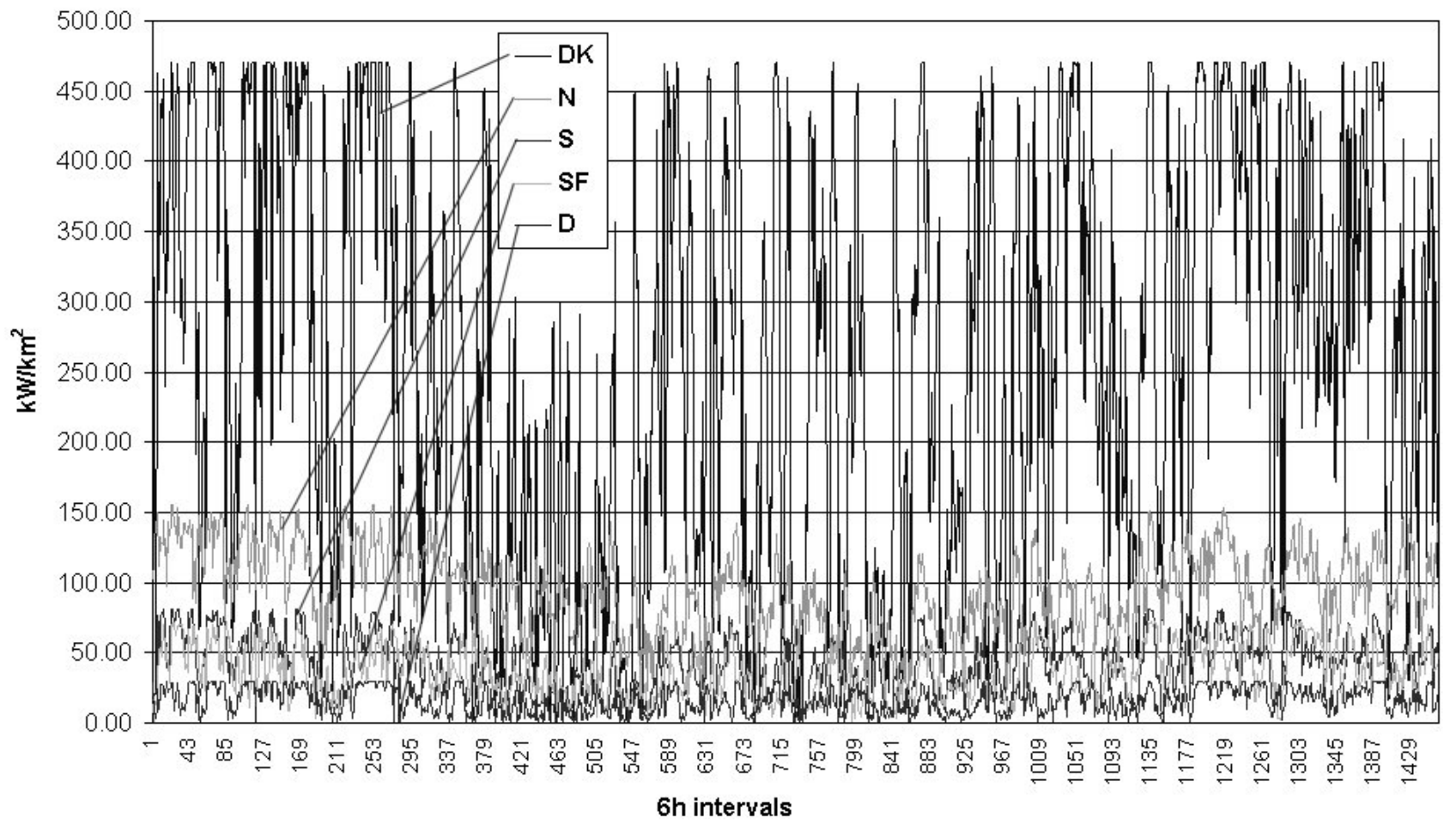




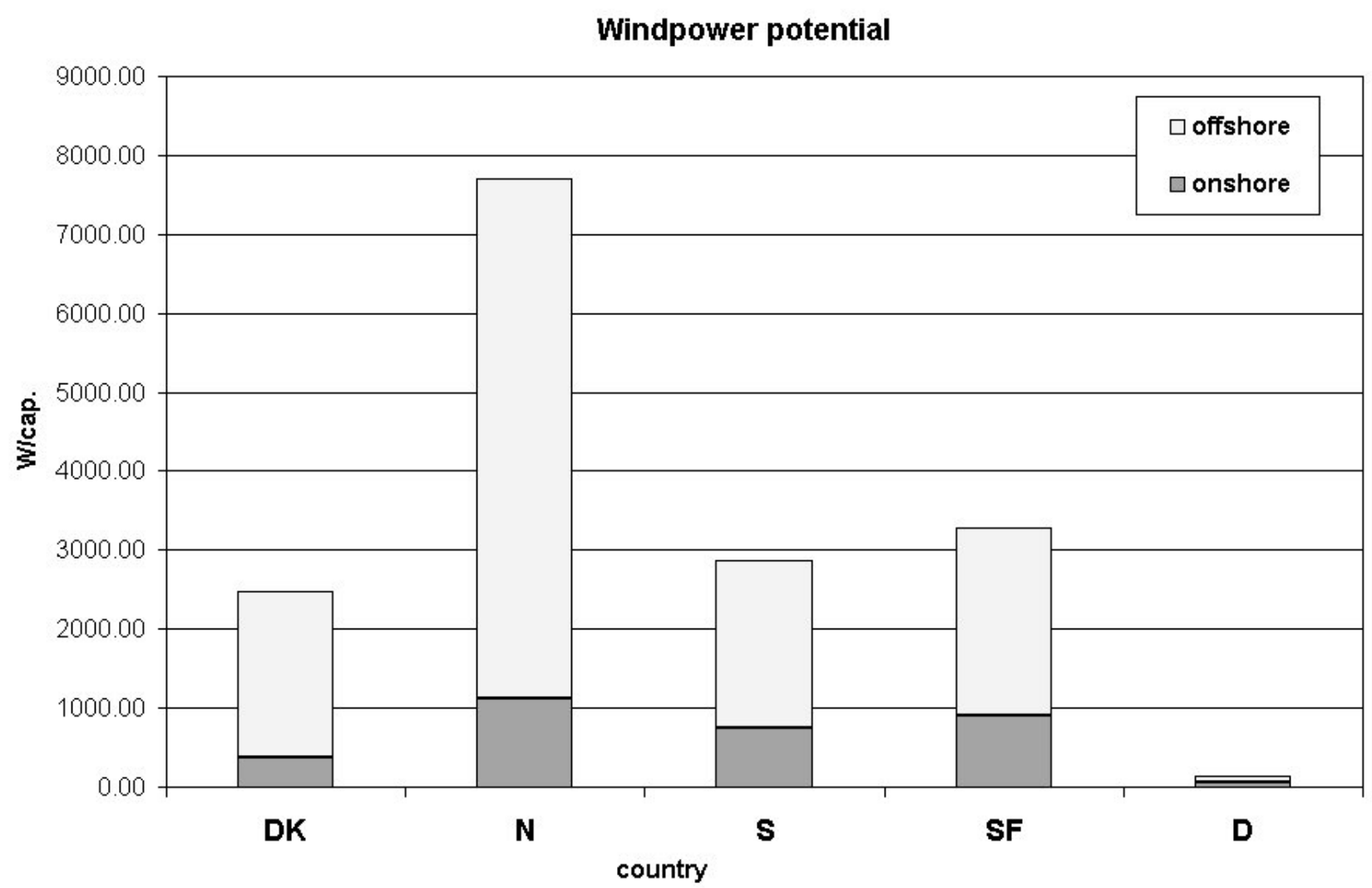

Figure 10. $a$ : The total potential for average wind power production in the five countries studied, divided by population and given as W/cap., with on- and off-shore contributions indicated. $b$ : Power curve assumed for all turbines in this study.

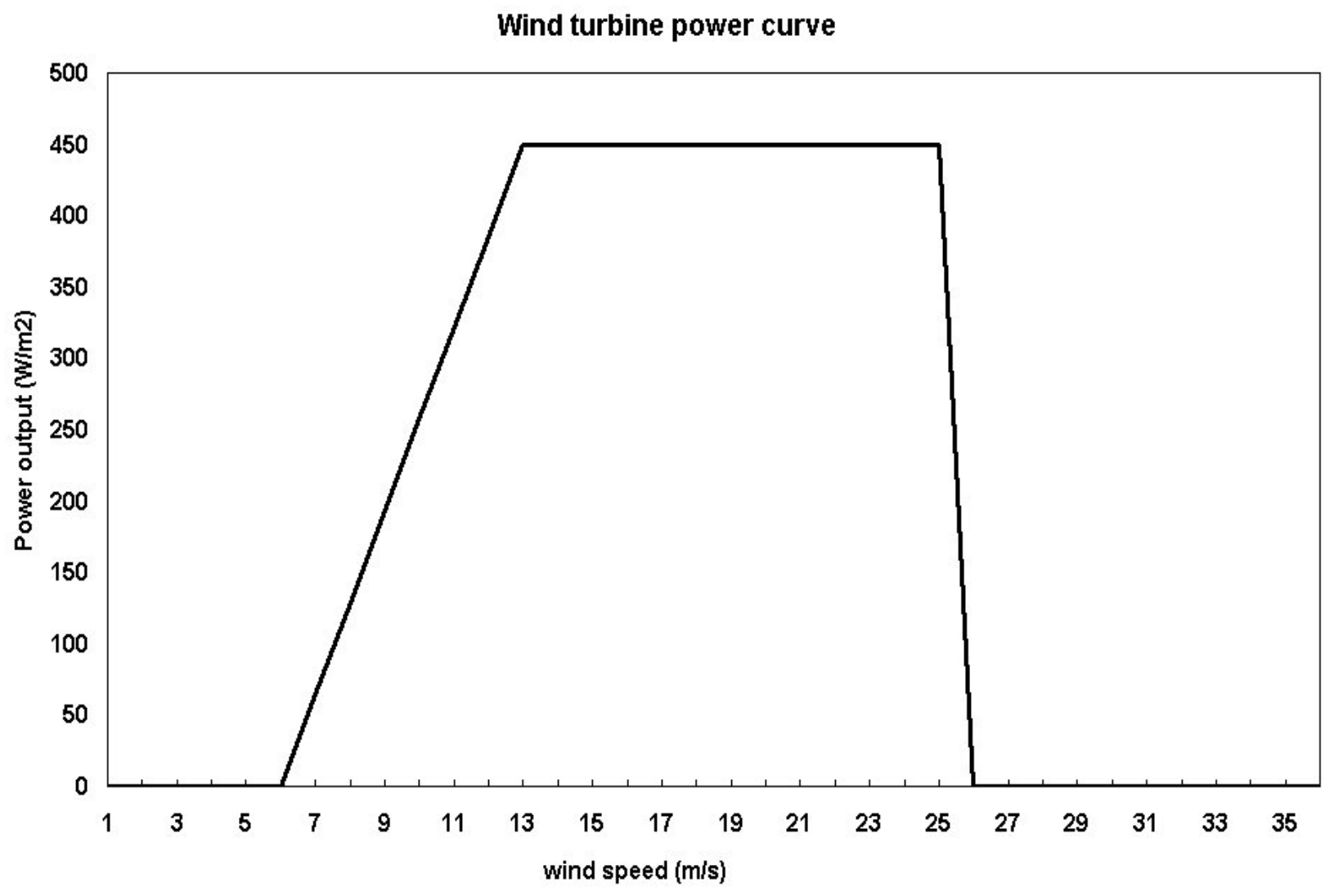


Danish disposition of wind electricity (except $\mathrm{H}_{2}$ conversion), middle 2060 scenario with $\mathrm{FC}$ and $\mathrm{H}_{2}$ stores

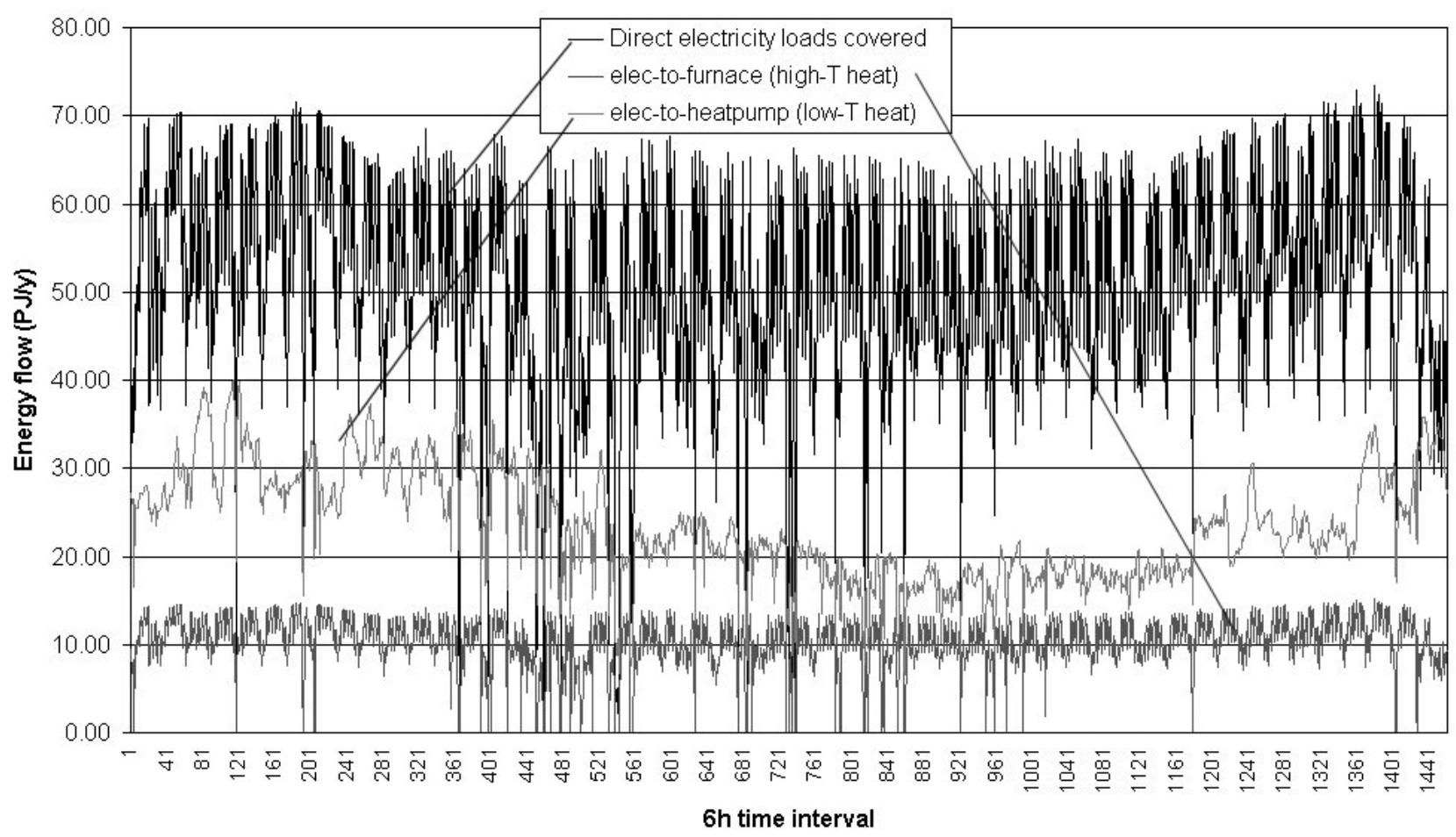

Figure 11. Disposition of wind power generated in the 2060 scenario for Denmark. Above are direct uses for dedicated power demands, for generating high-temperature process heat and for operating heat pumps. Below is shown the wind power used for hydrogen production (163 PJ/y), with the two other indirect uses indicated at bottom, in order to show their small size compared to hydrogen production (assumed to be by fuel cells in reverse operation).

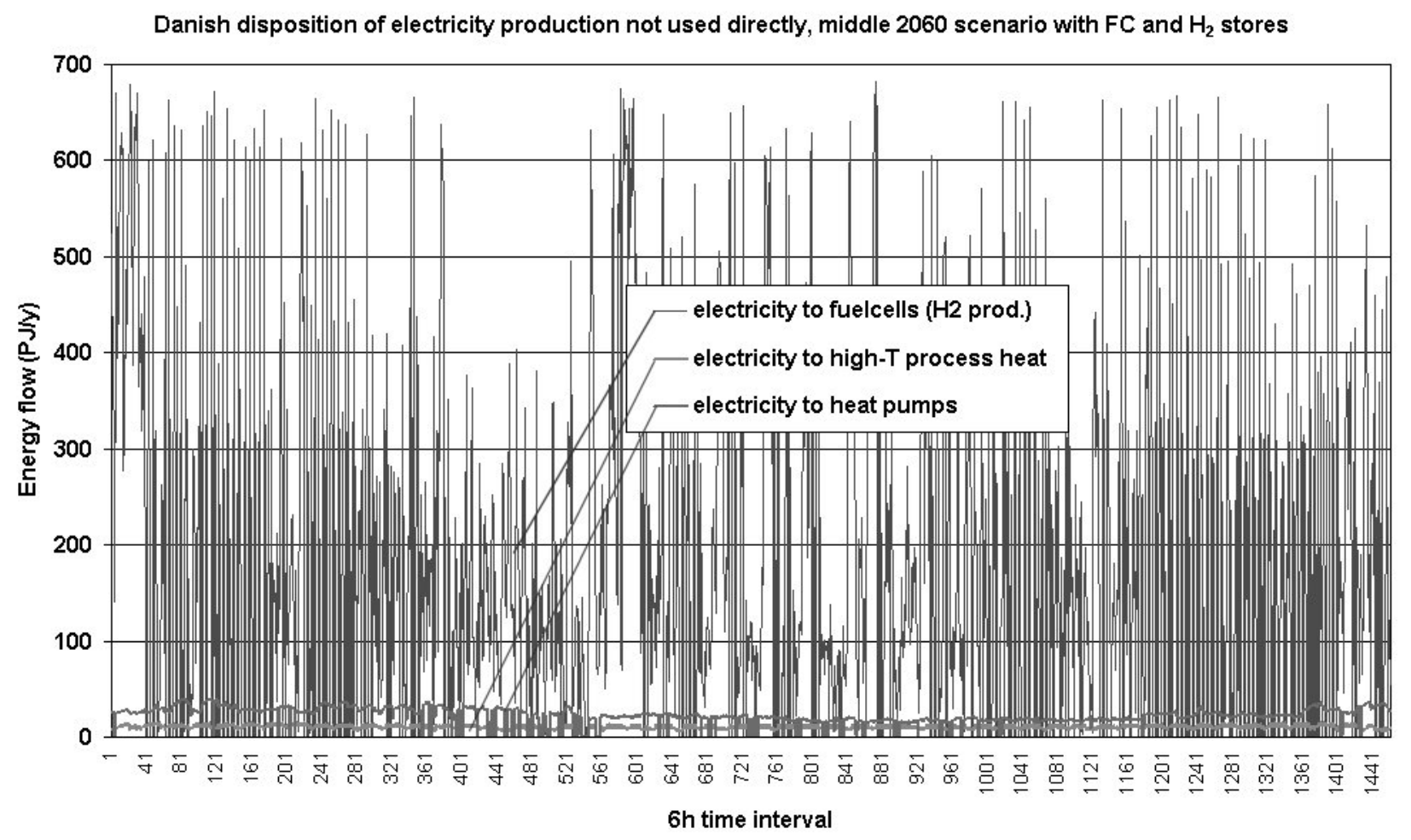




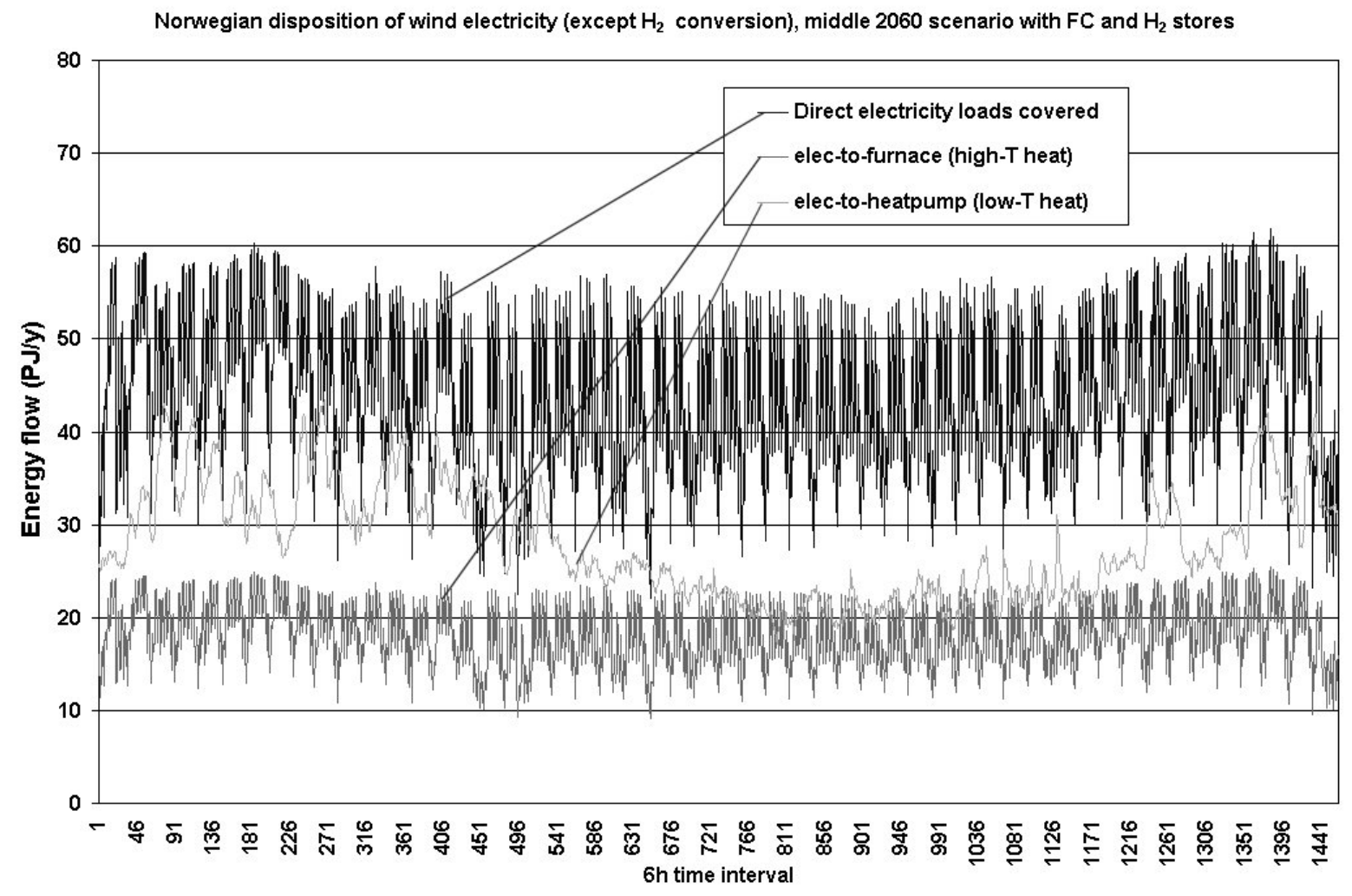

Figure 12. Disposition of wind power generated in the 2060 scenario for Norway. Due to the fact that the wind power duration curve is always substantially above zero (see Figure 7), loads may be covered by wind at nearly all times, although in practice, hydro power will also be used, leaving in all cases substantial amounts of power for export.

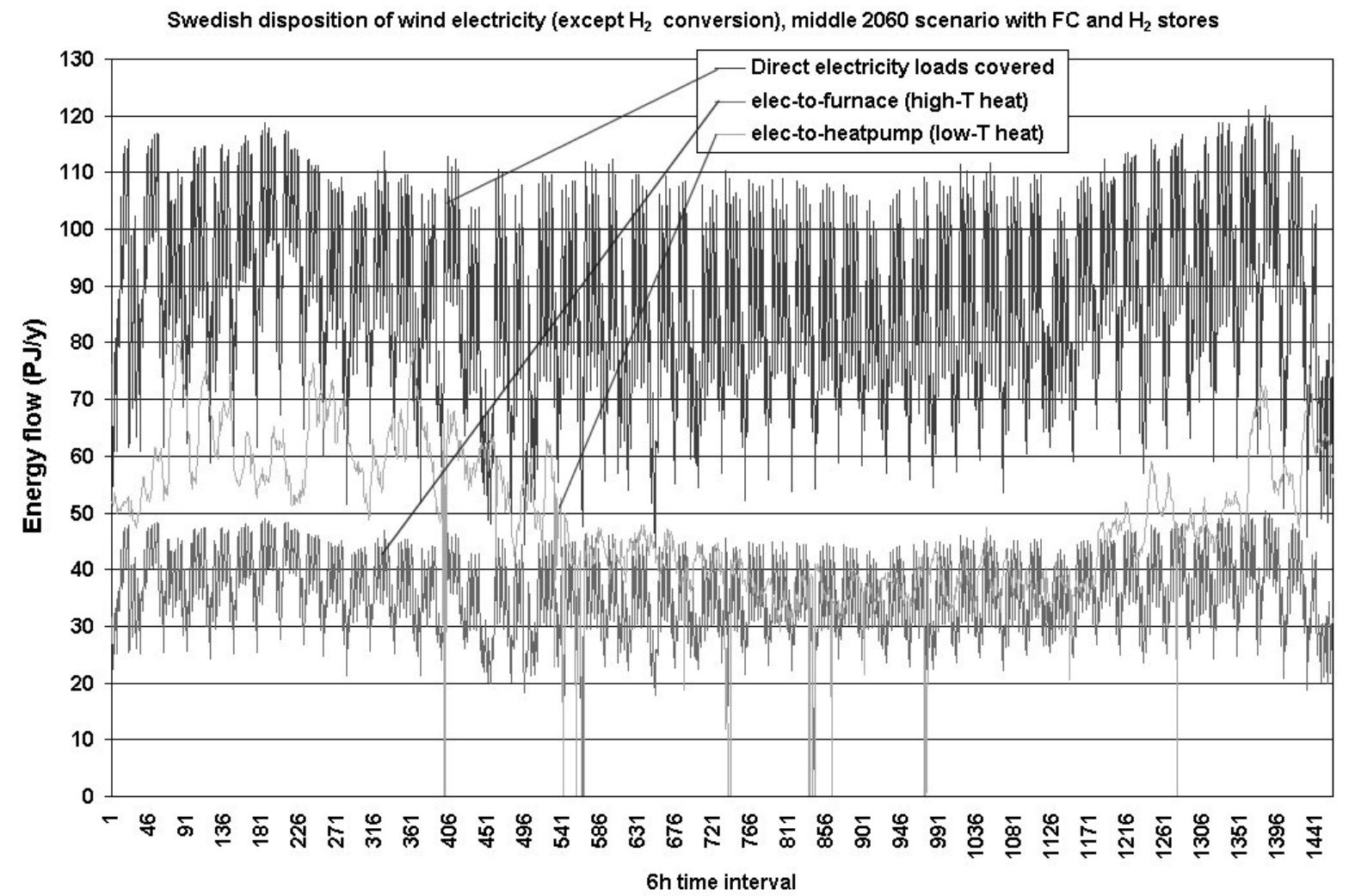

Figure 13. Disposition of wind power generated in the 2060 scenario for Sweden. 


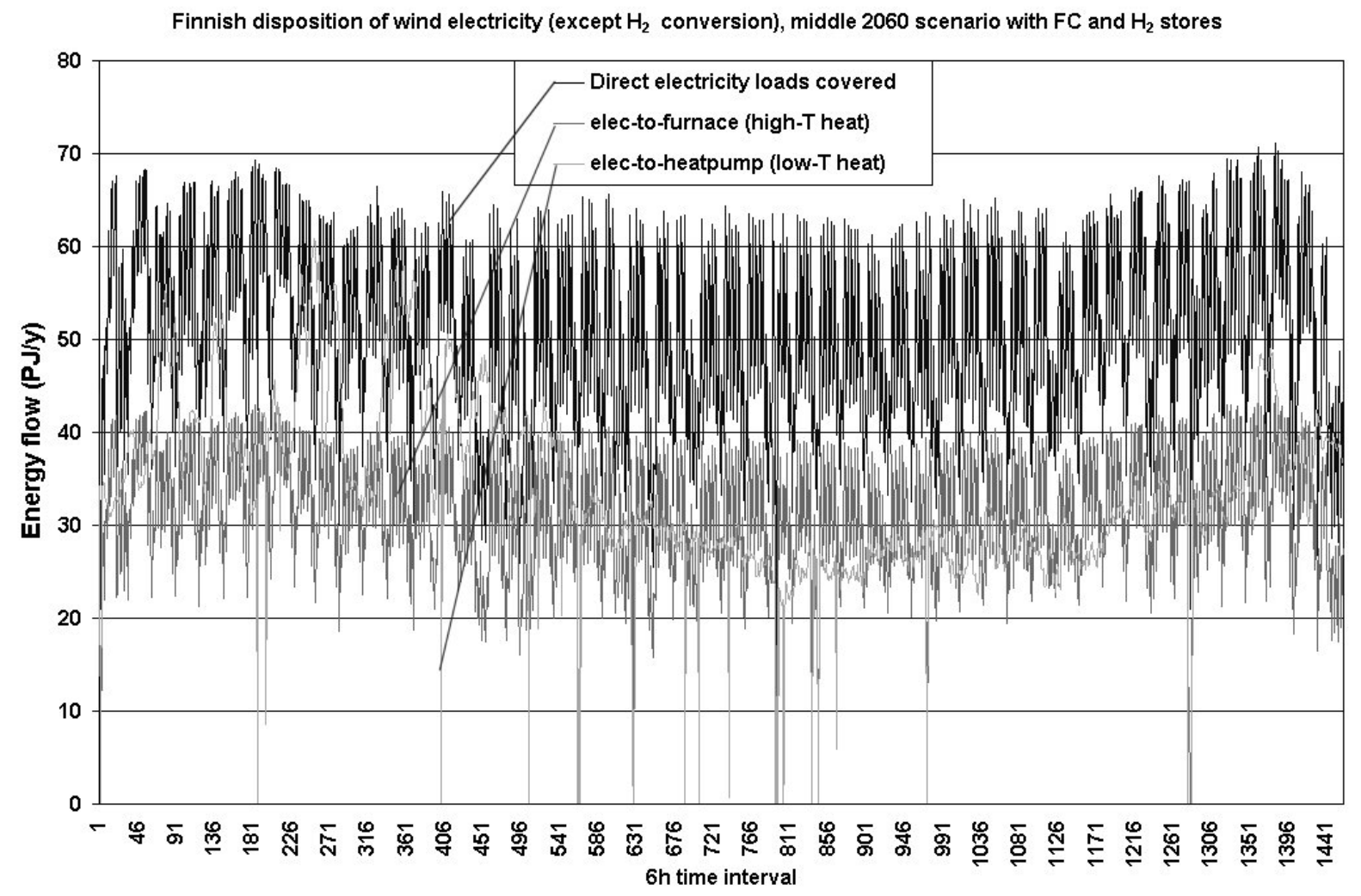

Figure 14. Disposition of wind power generated in the 2060 scenario for Finland.

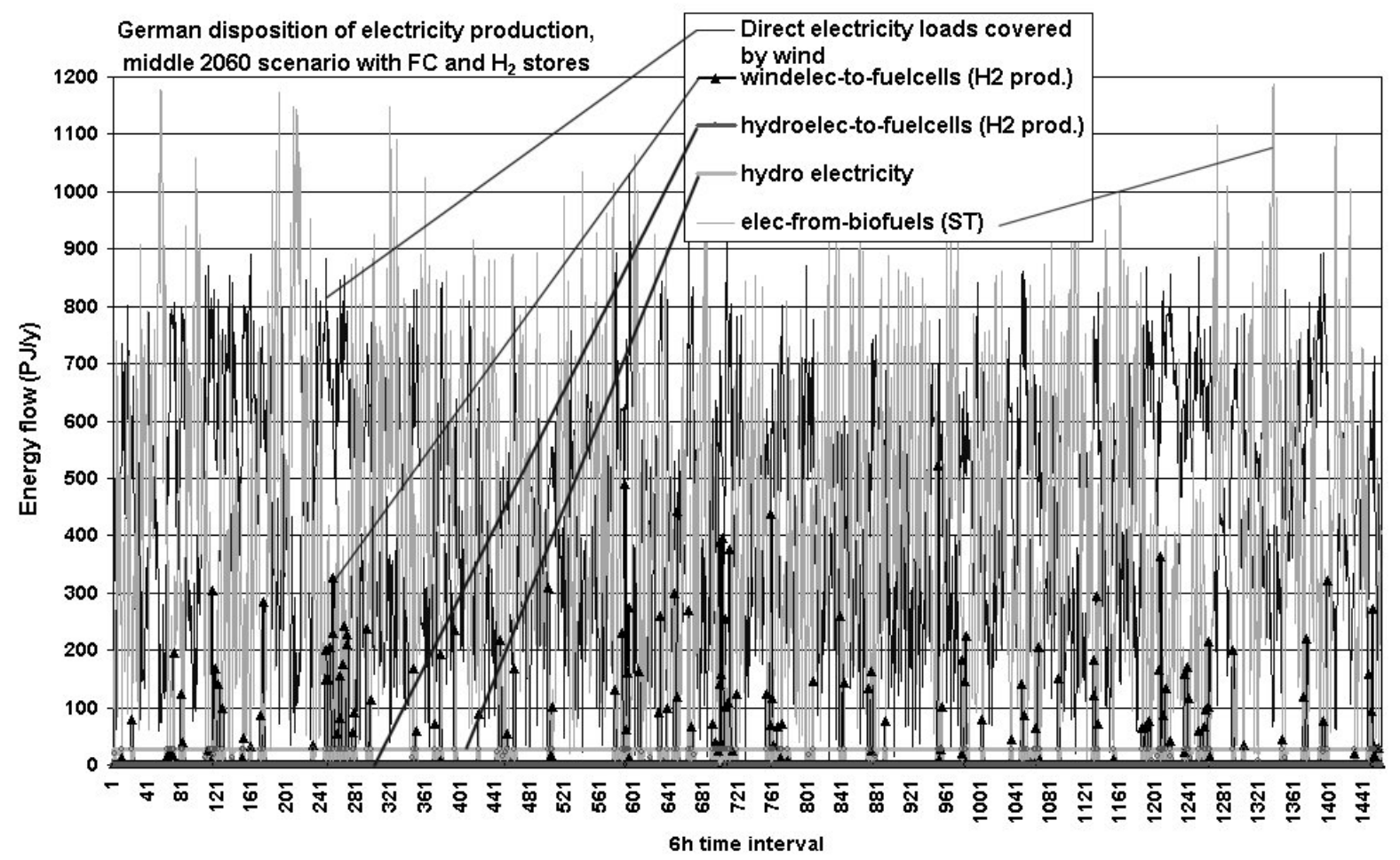

Figure 15. Disposition of wind power generated in the 2060 scenario for Germany in isolation. Only part of the dedicated electricity demands can be covered by wind. Any surpluses are converted to hydrogen, but the largest supplier of electric power is stipulated to be steam turbines (ST) fuelled by biomass, in this scenario not considering imports of power. However, the indigenous sources of biomass are also insufficient, and the deficit is on average $980 \mathrm{PJ} / \mathrm{y}$. 
Denmark: Filling of hydrogen store (capacity 1.37 PJ), 2060 scenario with $\mathrm{FC}$ and stores

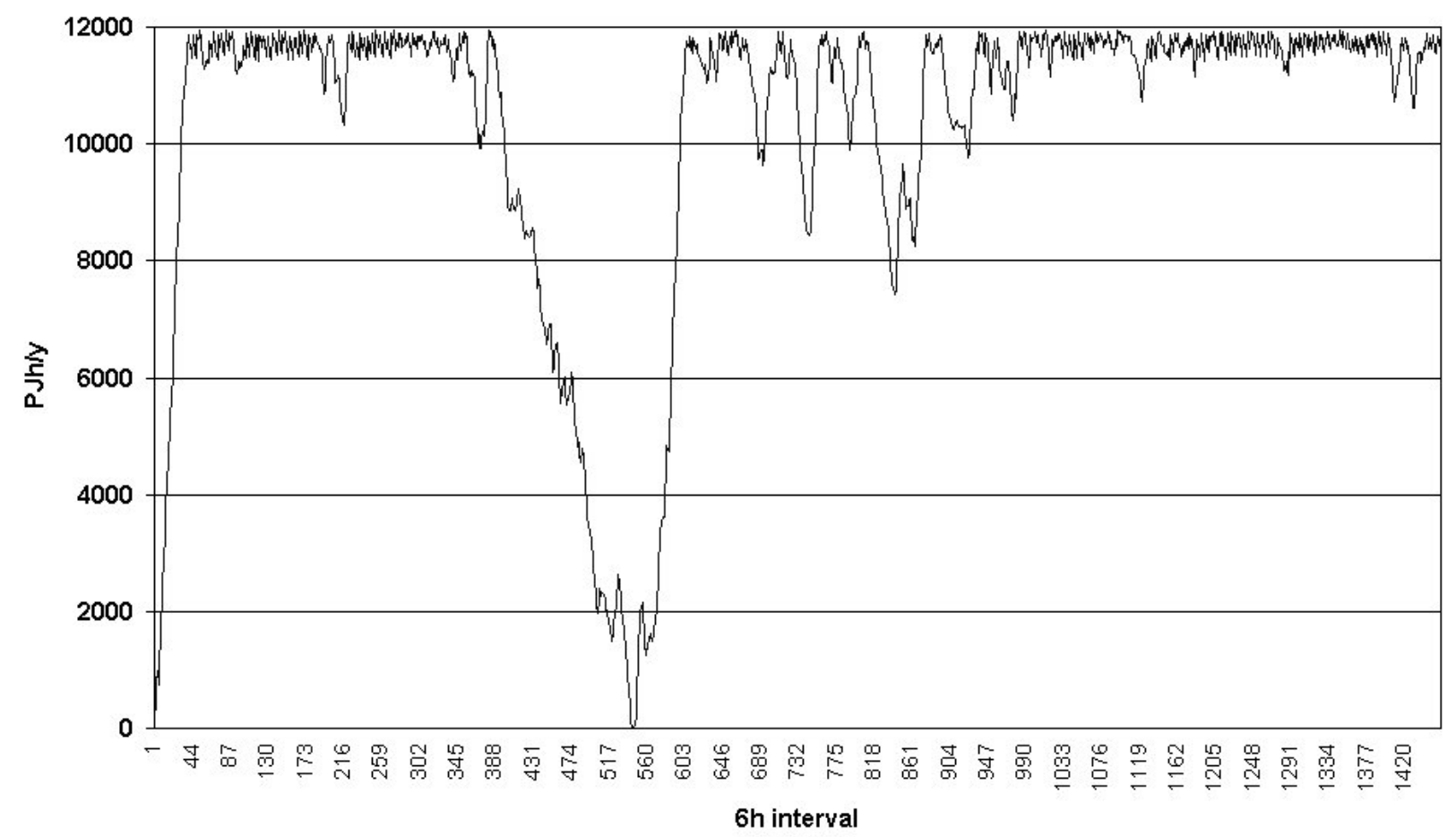

Figure 16. Variations in filling of hydrogen stores in Denmark, over the simulation year.

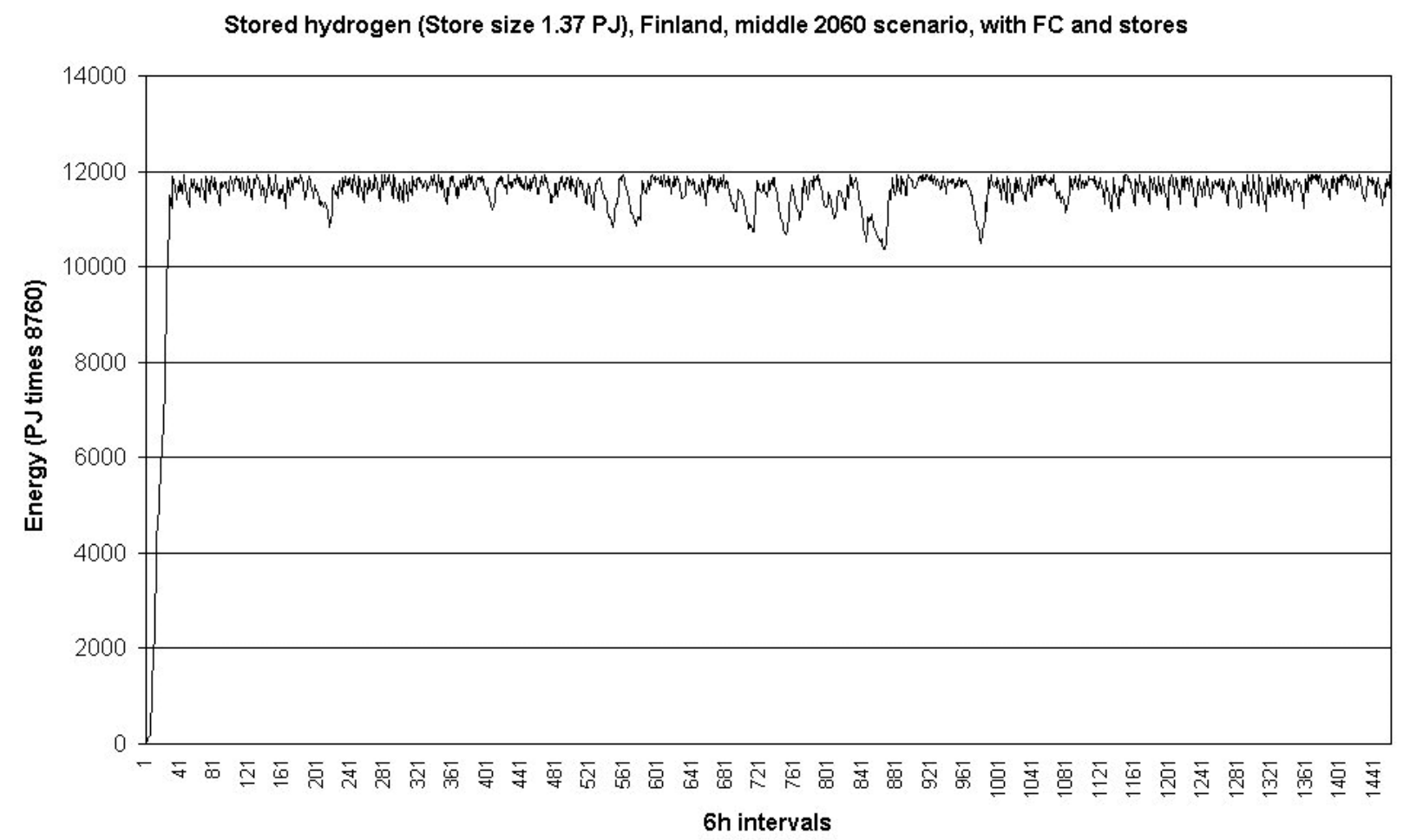

Figure 17. Variations in filling of hydrogen stores in Finland, over the simulation year. 


\section{Hydroreservoir filling (Norway)}

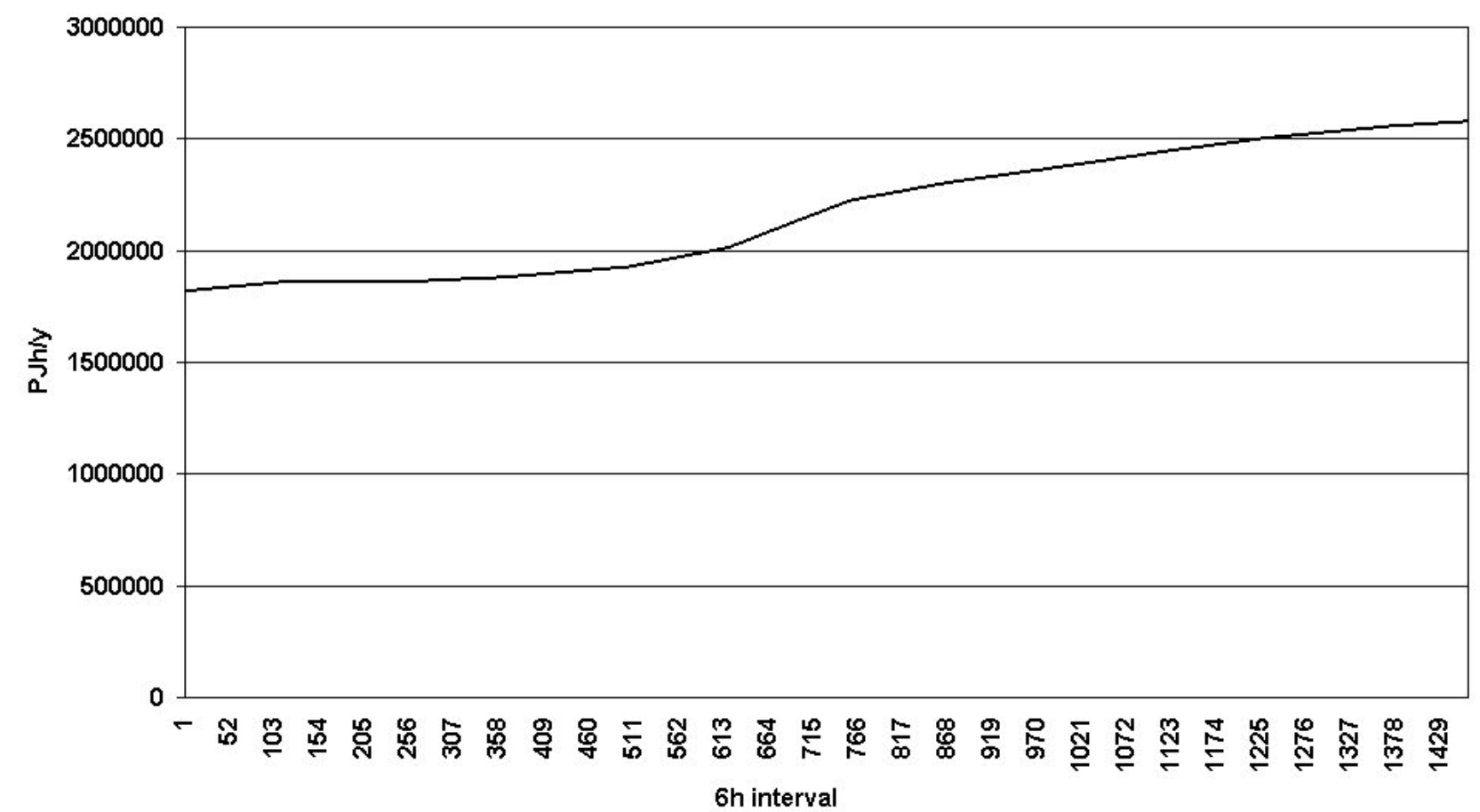

Figure 18. Water level (in energy units) of Norwegian hydro reservoirs, in isolated scenario where a large surplus is built up during the year.

Danish use of hydrogen and liquid biofuels in middle 2060 scenario with $\mathrm{H} 2$ and stores

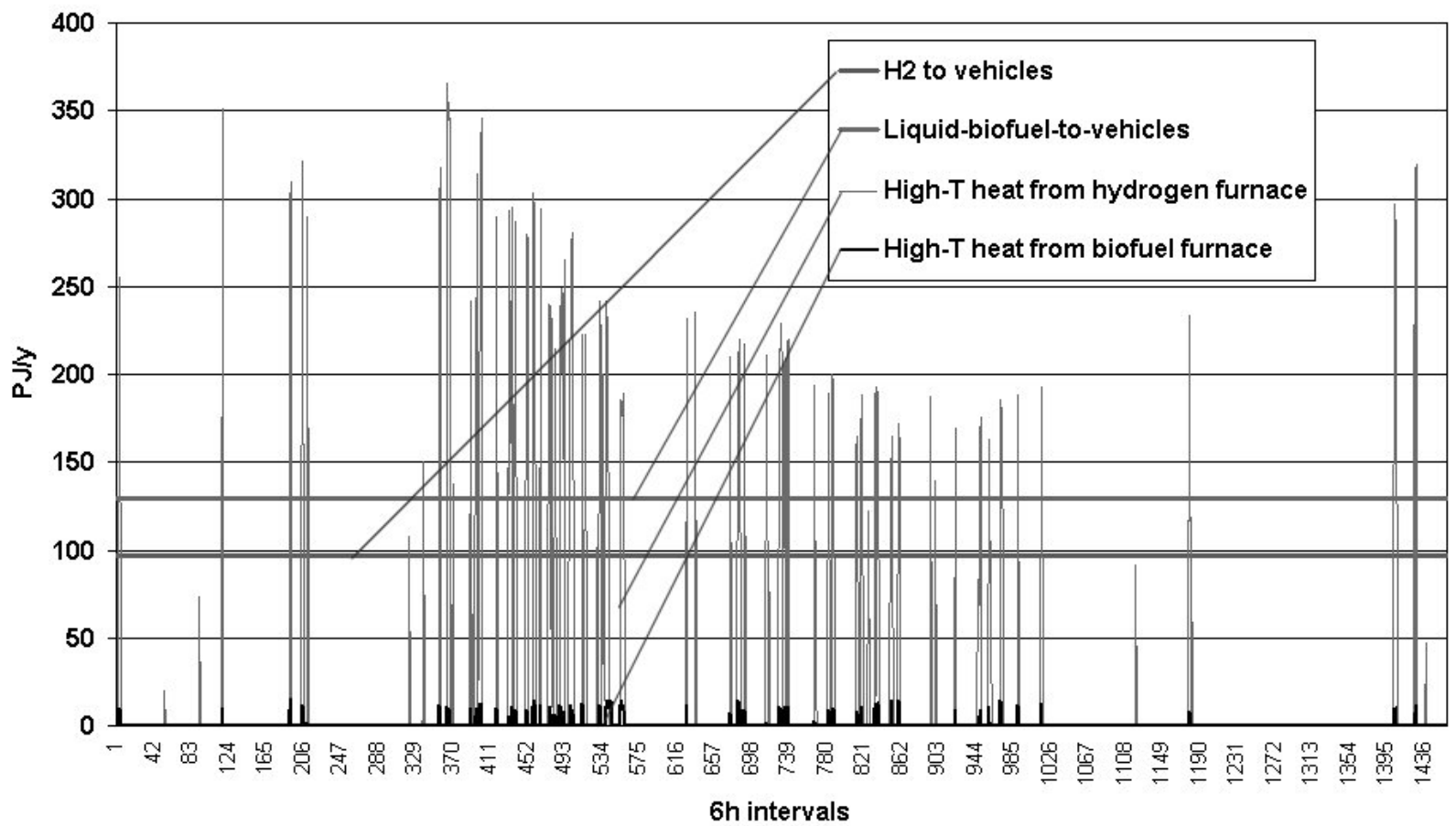

Figure 19. Disposition of produced biofuels and hydrogen in the 2060 scenario for Denmark. Half of the transportation end-use energy is covered by hydrogen and half by biofuels. For producing process heat, hydrogen has priority over biofuels, for reasons of environmental impacts. Most high-temperature heat is produced by electric furnaces, so fuels are used only in periods of insufficient wind. 
Norwegian use of hydrogen and liquid biofuels in middle 2060 scenario with $\mathrm{H}_{2}$ and stores

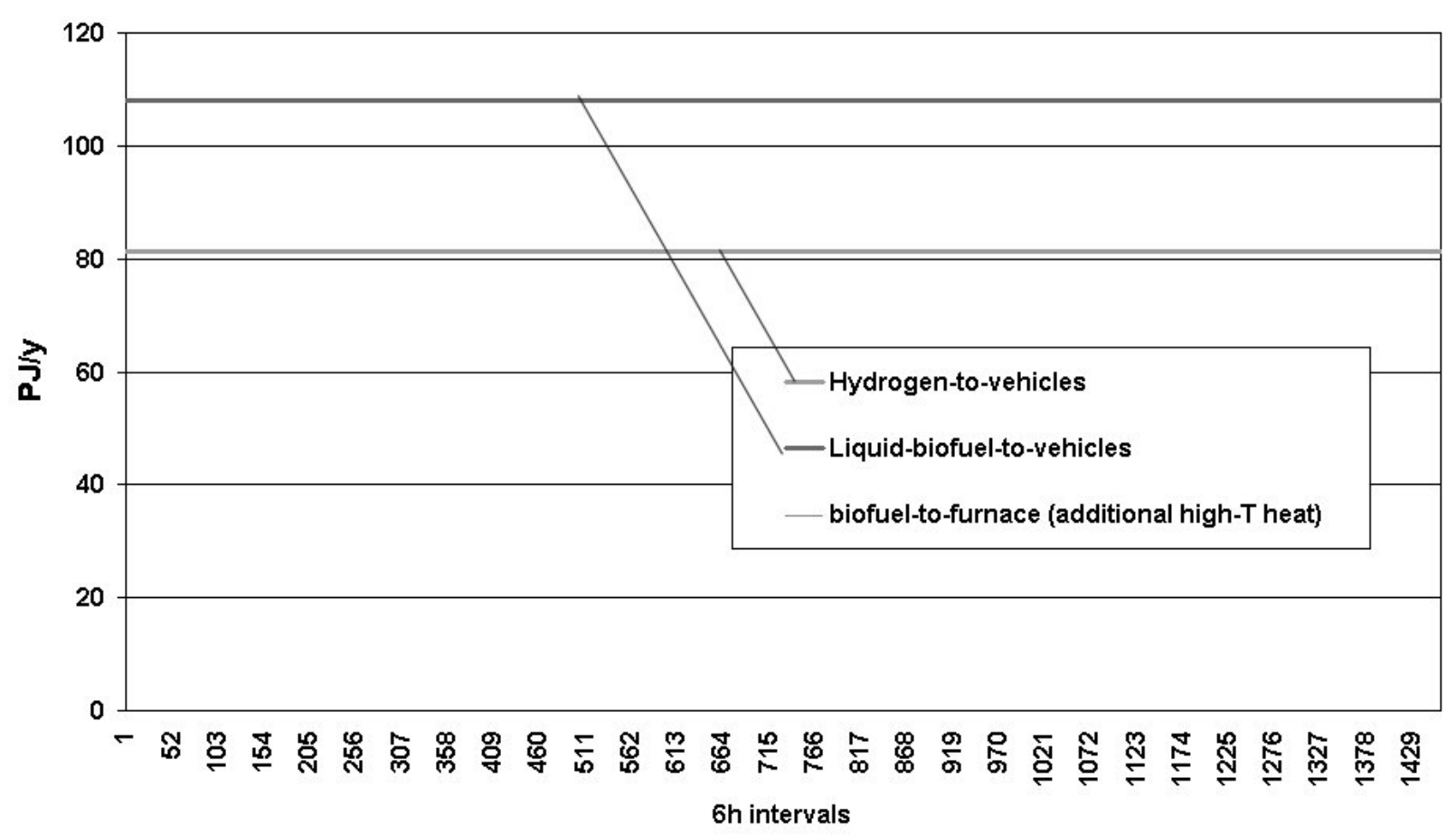

Figure 20. Use of hydrogen and biofuels for transportation in the 2060 scenario for Norway. High-temperature process heat is already fully covered by electric furnaces. Sweden and Finland have similar patterns.

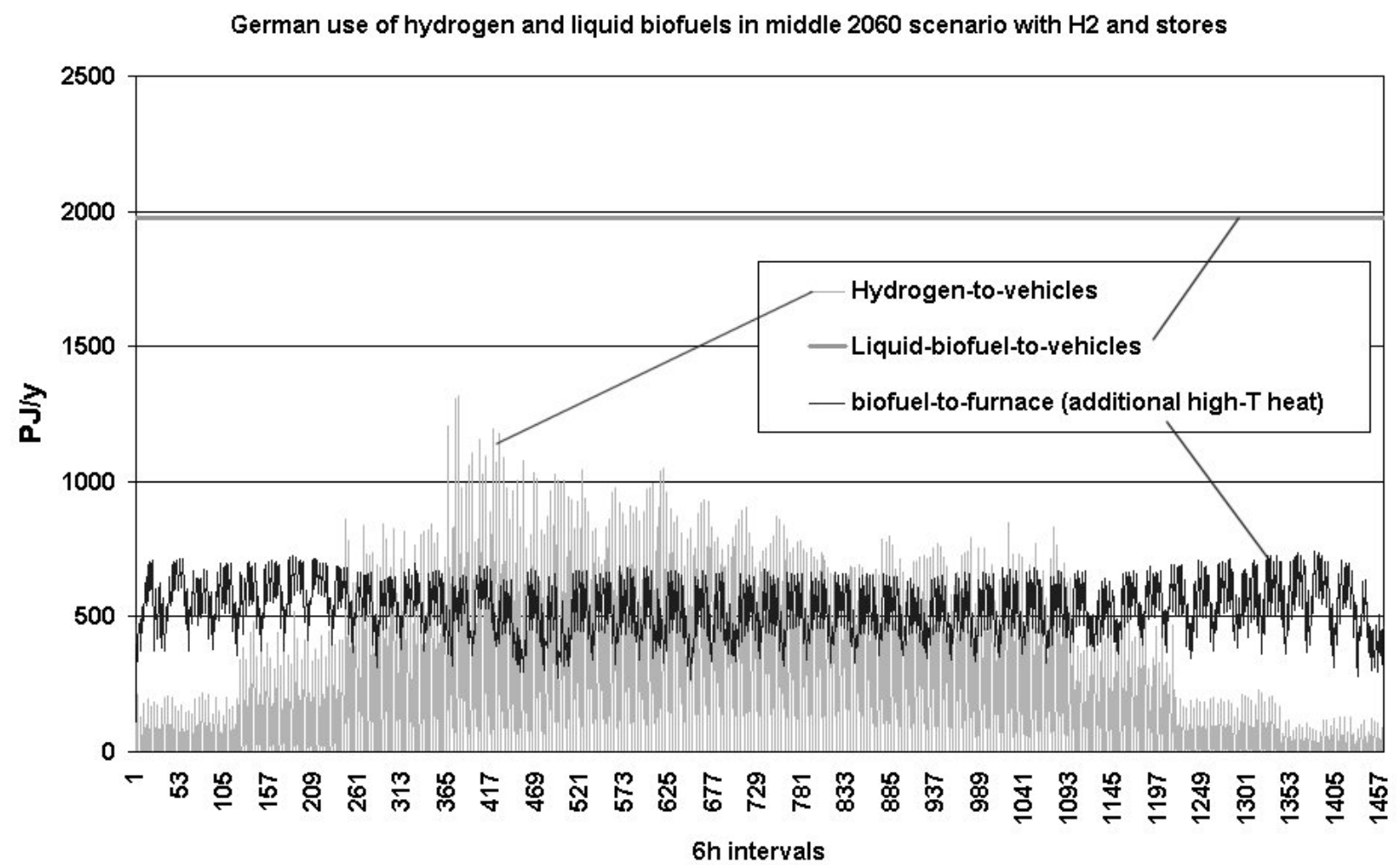

Figure 21. Use of hydrogen and biofuels in the 2060 scenario for Germany in isolation. High-temperature process heat is seen to be largely covered by biofuelled furnaces. Hydrogen produced by wind and hydro is insufficient to satisfy the $50 \%$ demands in the transportation sector, particularly during winter months. As mentioned in the caption below Figure 15 , there is a substantial requirement for biofuel imports to the German transportation sector. 


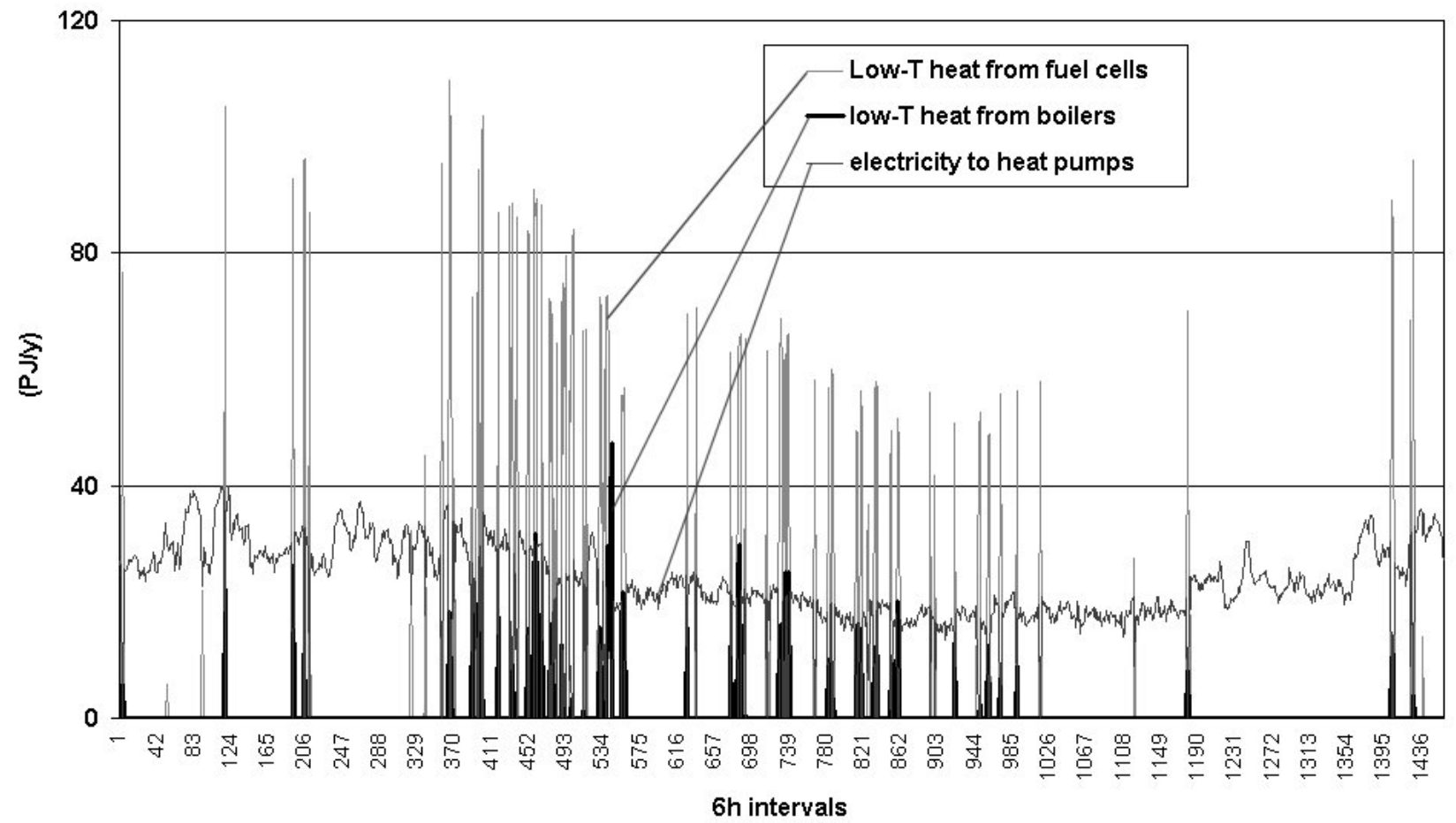

Figure 22. Provision of low-temperature heat in Danish 2050 scenario, from fuel cell heat losses, electric heat pumps and as lowest priority plain boilers using biomass fuel. The other countries exhibit fairly similar distributions.

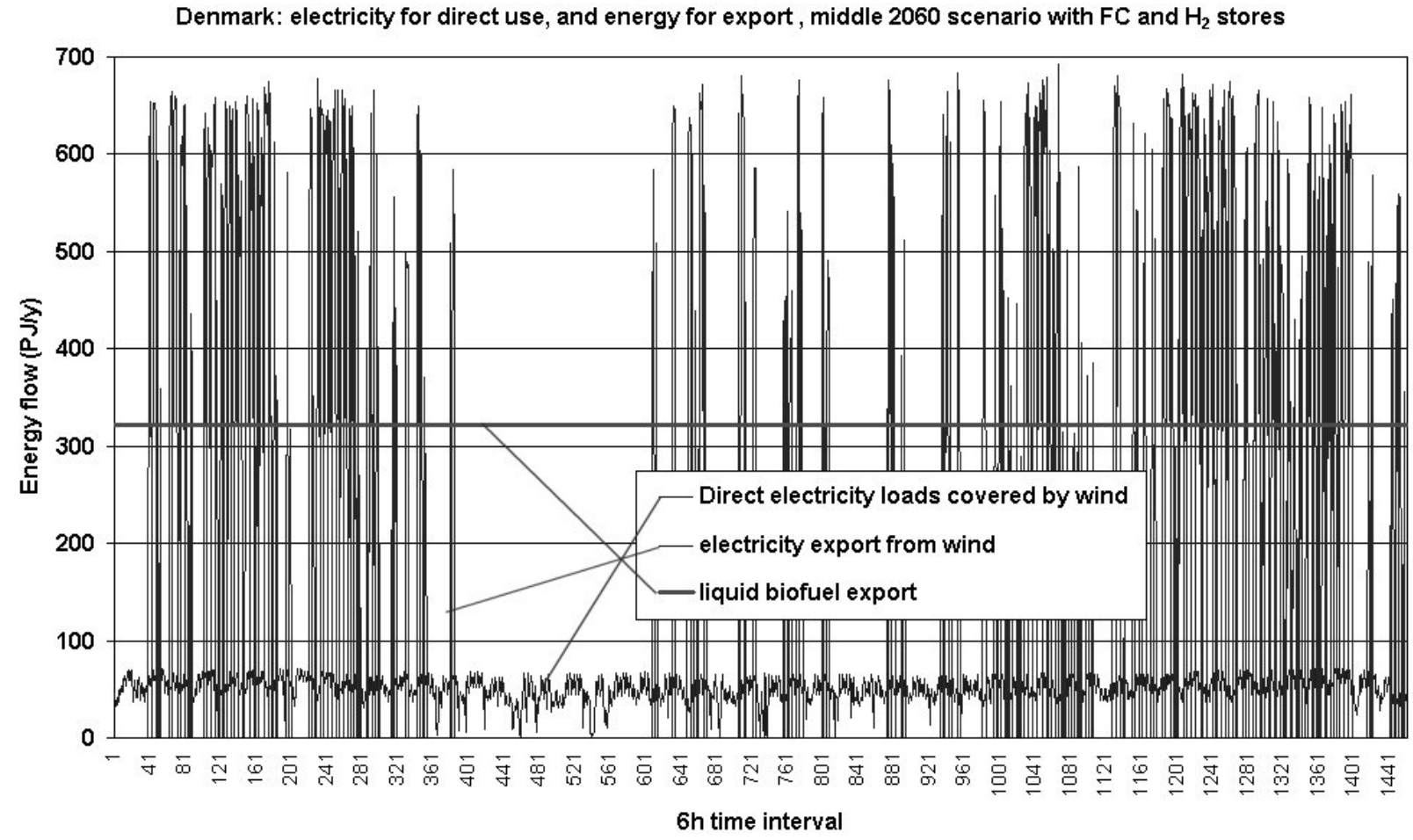

Figure 23. Potential energy exports from Denmark in the 2050 scenario, indicating a liquid biofuel export potential spread evenly over the year (although it does not have to be) and an electricity export potential in periods of wind power surpluses. The direct coverage of domestic loads by wind is shown at bottom, indicating the occasionally very large surplus available for export during particular hours (suited for hydrogen production, which could be accomplished in the country importing, in order to avoid long-distance piping of hydrogen). 


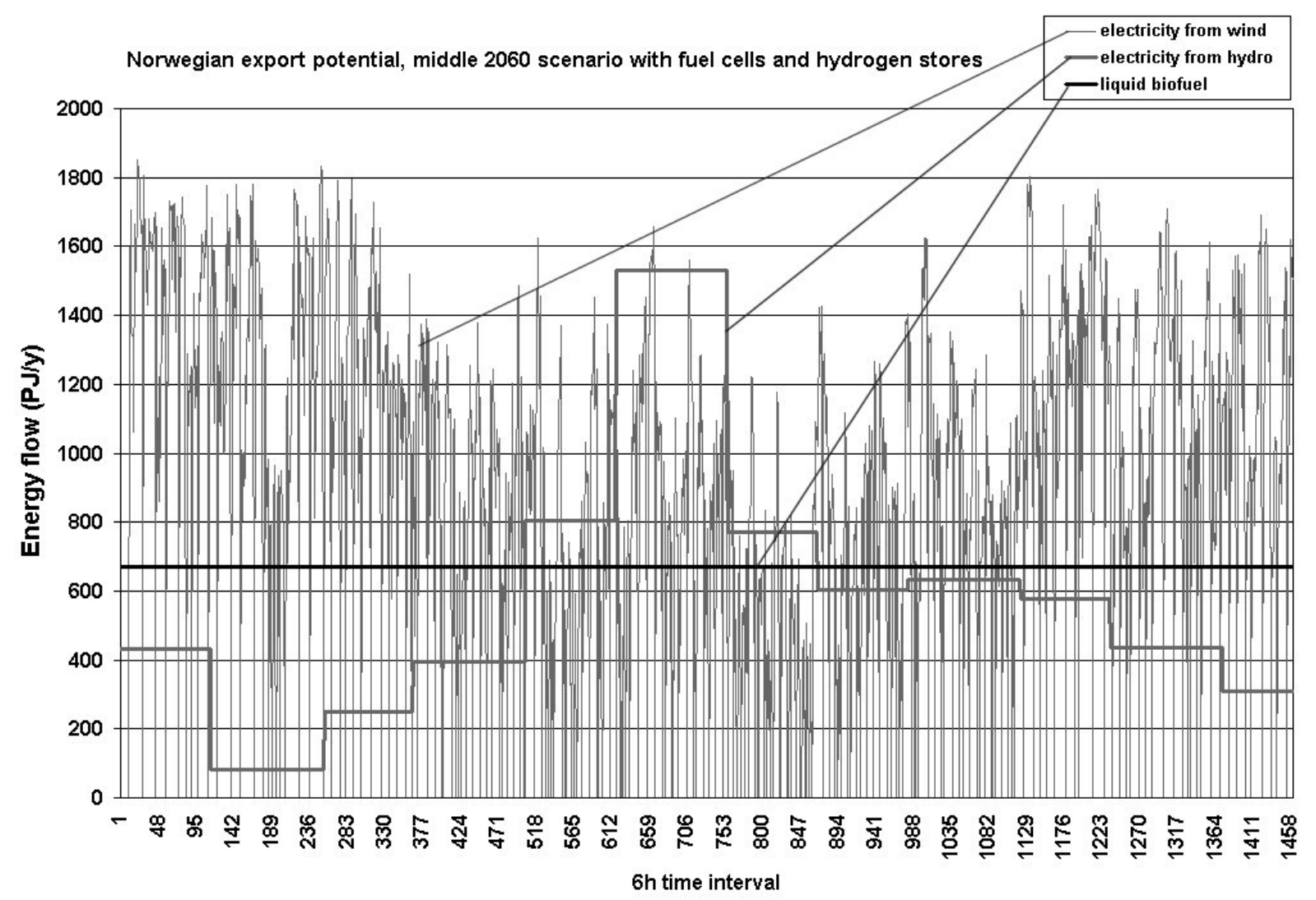

Figure 24. Potential energy exports from Norway in the 2050 scenario, indicating a biofuel and a variable wind power export potential, and further a hydro power export potential, which is shown as proportional to the monthly inflow of water into the reservoirs, although this may not be the actual distribution of exports.

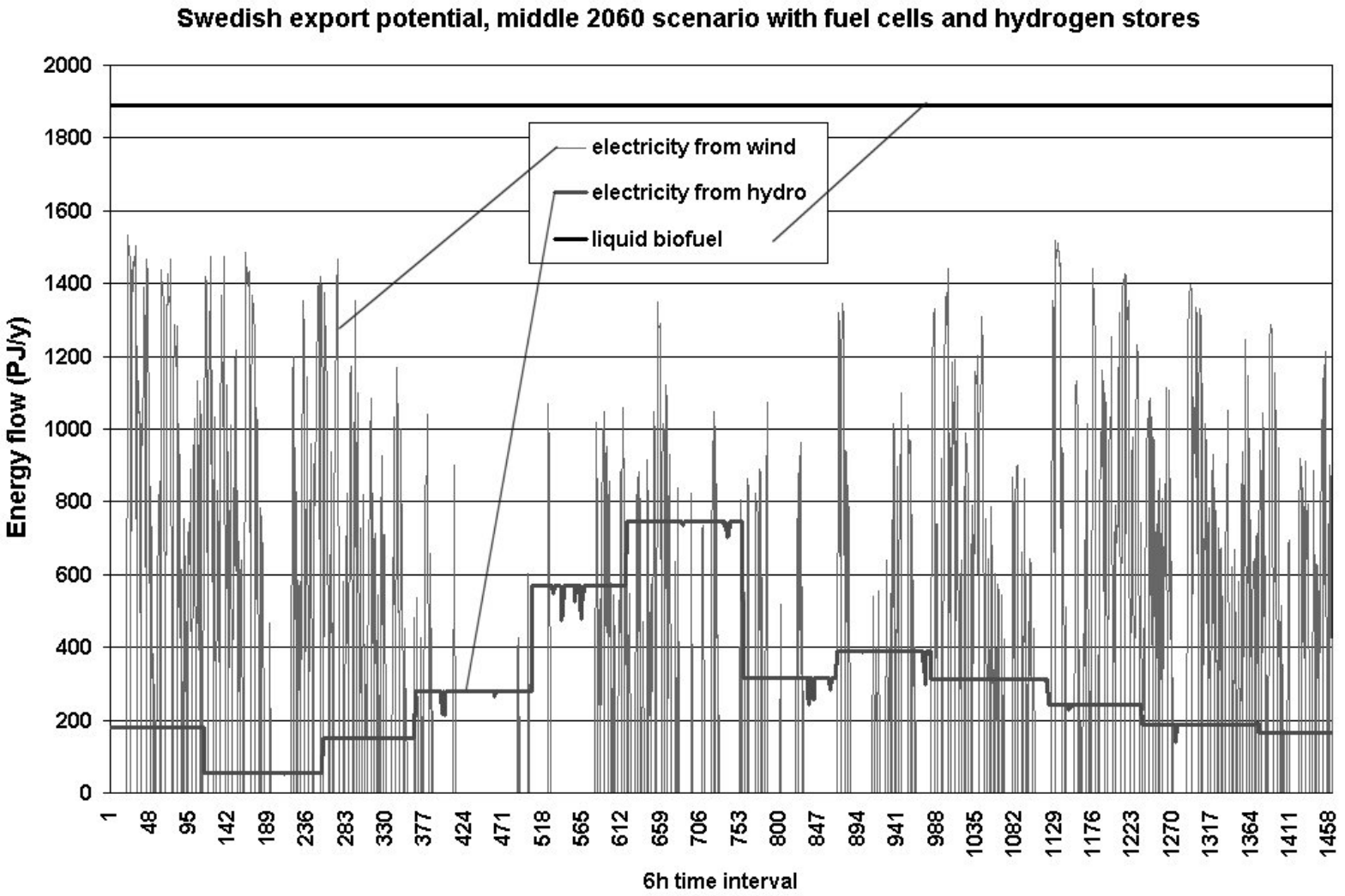

Figure 25. Potential energy exports from Sweden in the 2050 scenario. Cf. caption to Figure 24. 


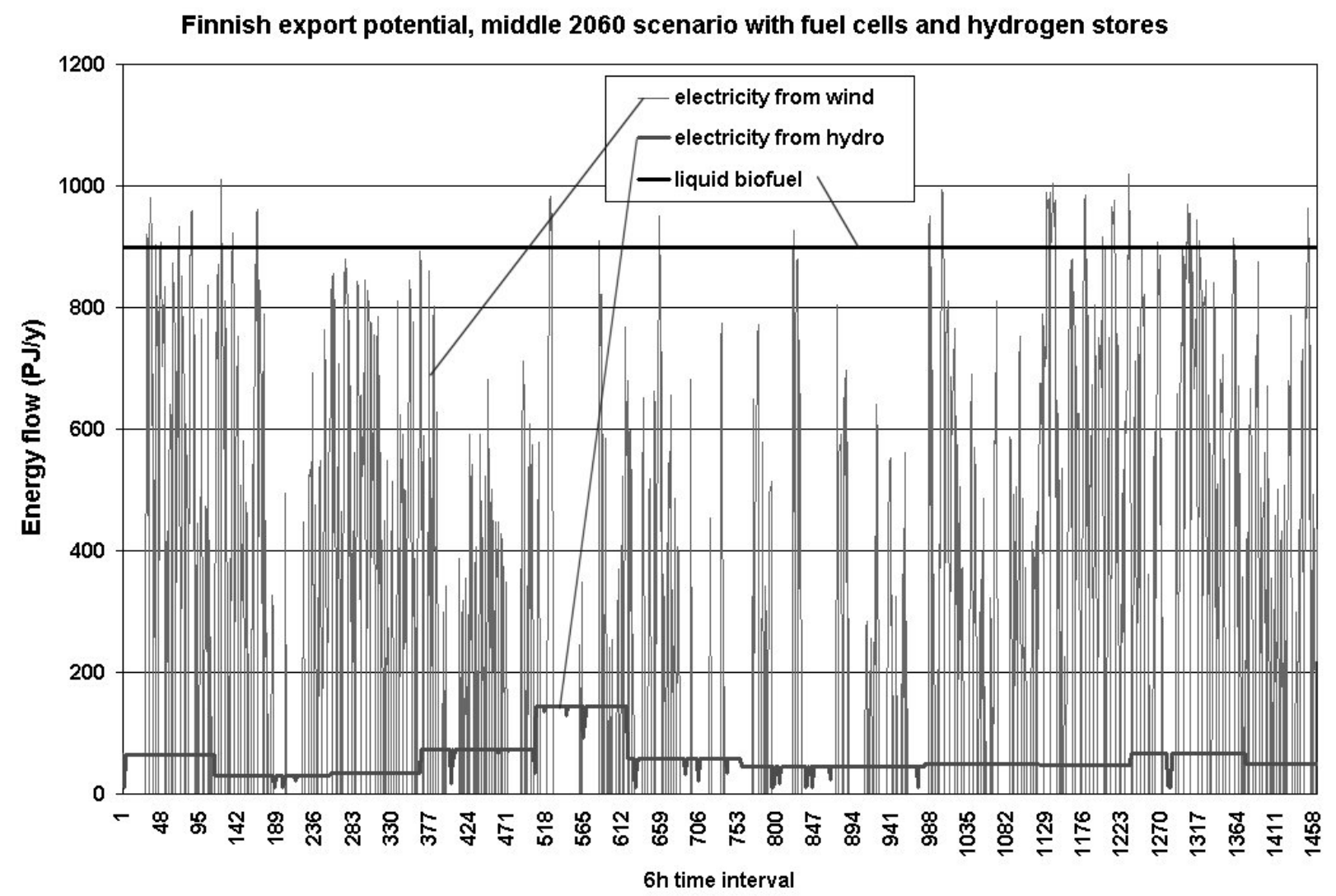

Figure 26. Potential energy exports from Finland in the 2050 scenario. Cf. caption to Figure 24.

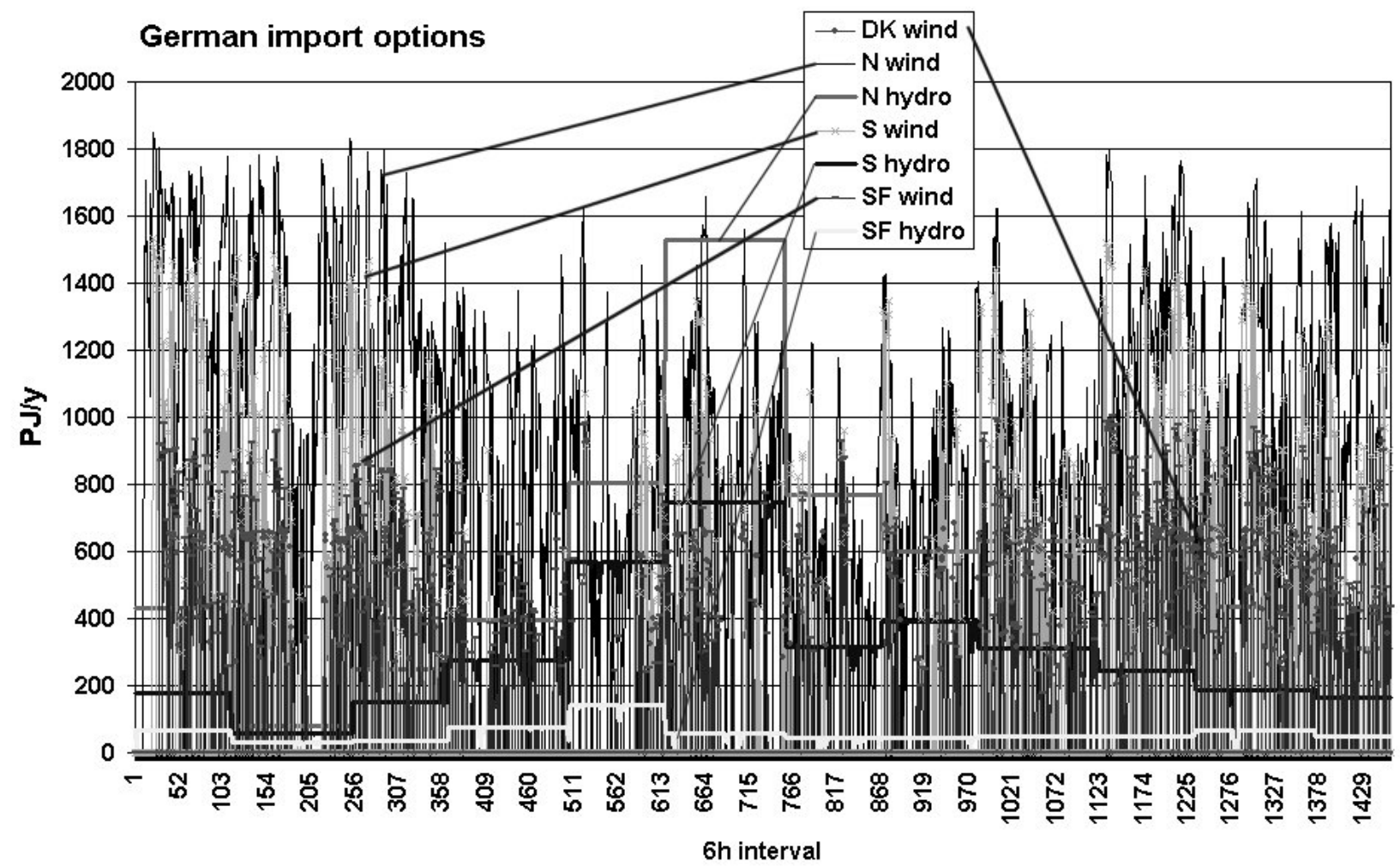

Figure 27. Import options for Germany, which in the 2060 has a considerable import need. The potential Nordic exports from Figures 23-26 are plotted together, in order to indicate their relative size. The total availability of German options for import exceeds the requirements, and a choice may be made between electricity or fuel imports, or a combination of these. Also imports from nearby countries may be preferable, due to transmission costs. 


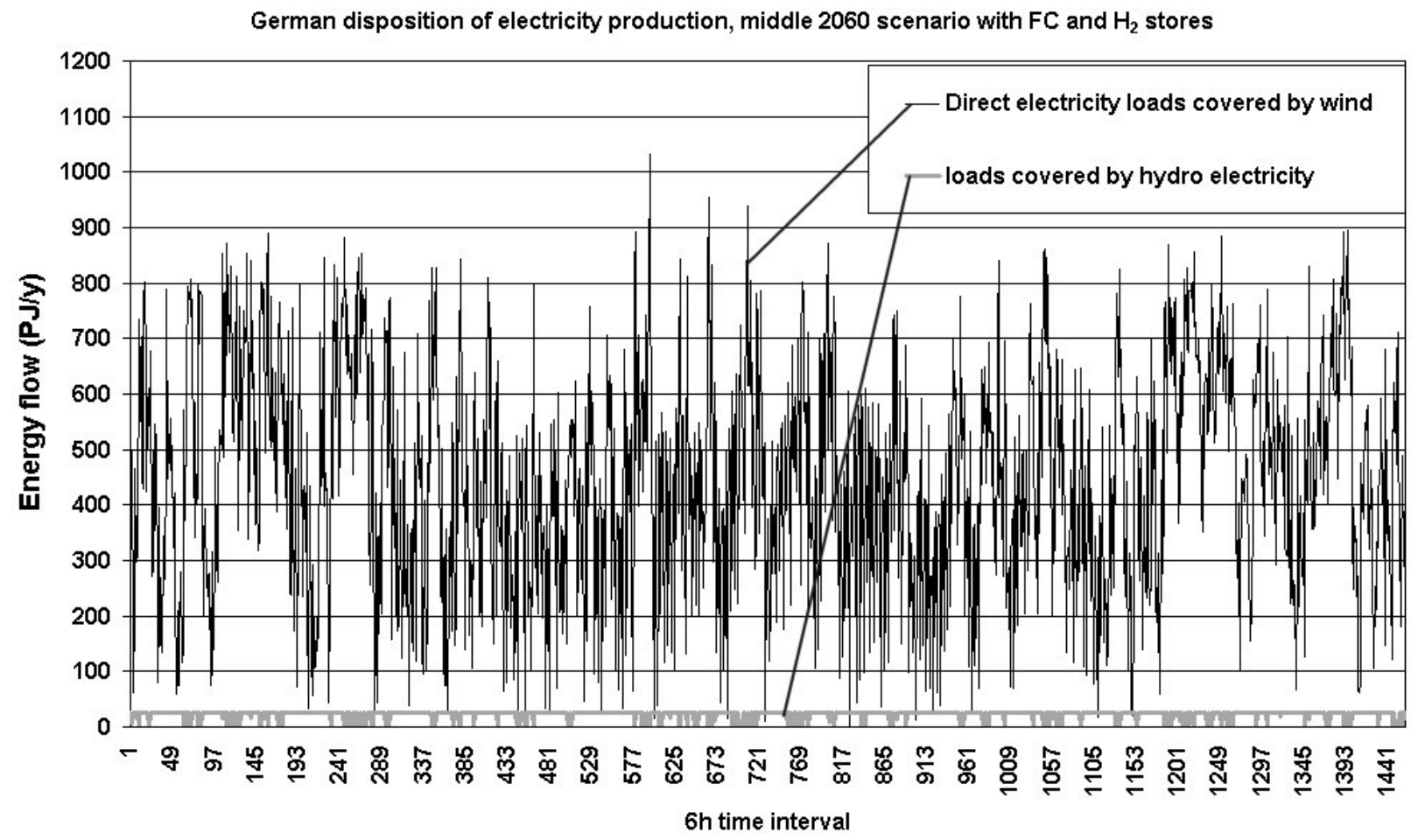

Figure 28. Disposition of wind power generated in the 2060 scenario for Germany as well as imports of power from the Nordic countries (direct uses above, indirect ones below). Availability of electricity and fuel imports options makes the disposition of indigenous production different from that in the isolated scenario. The hydrogen production from electric power will be used in the transportation sector.

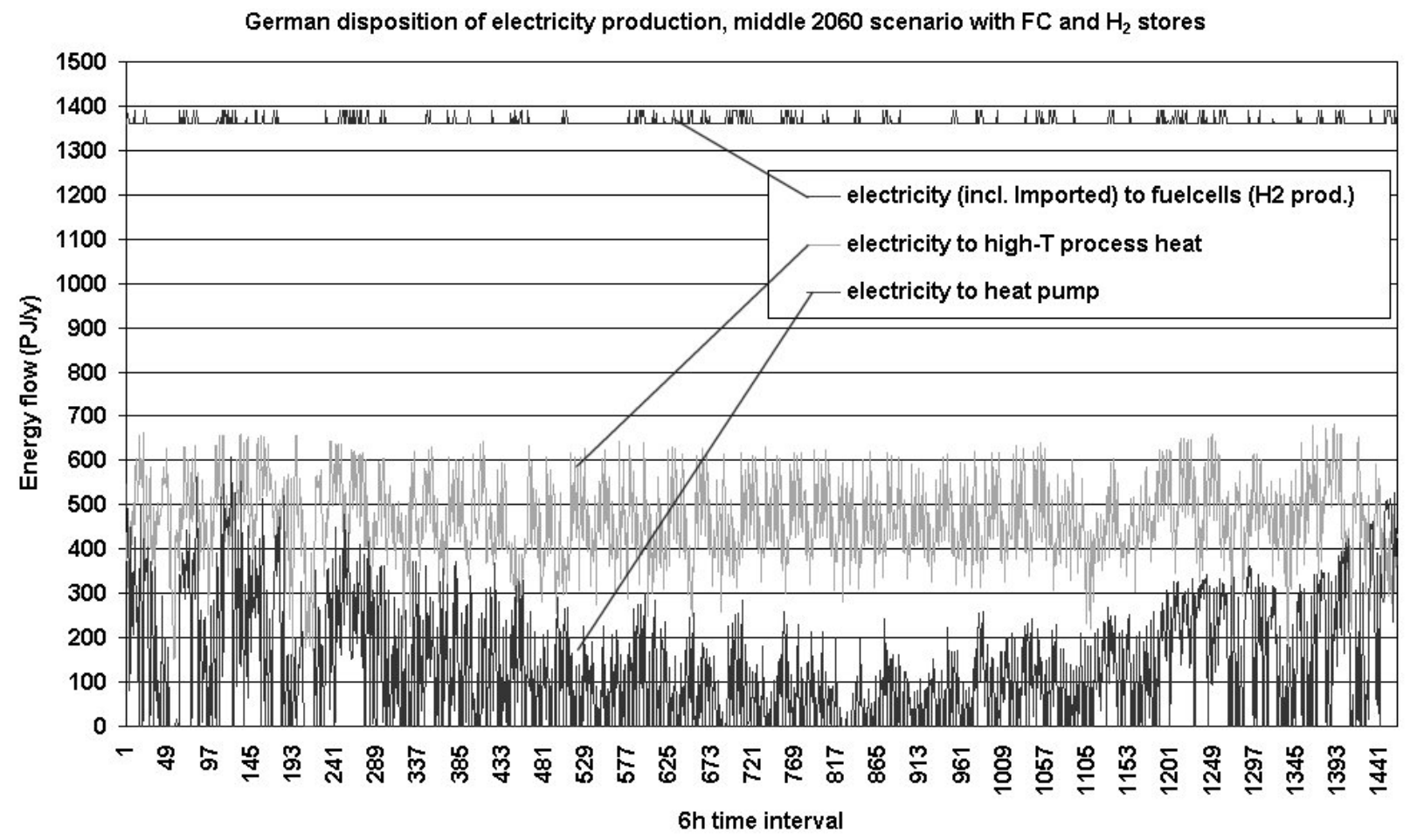




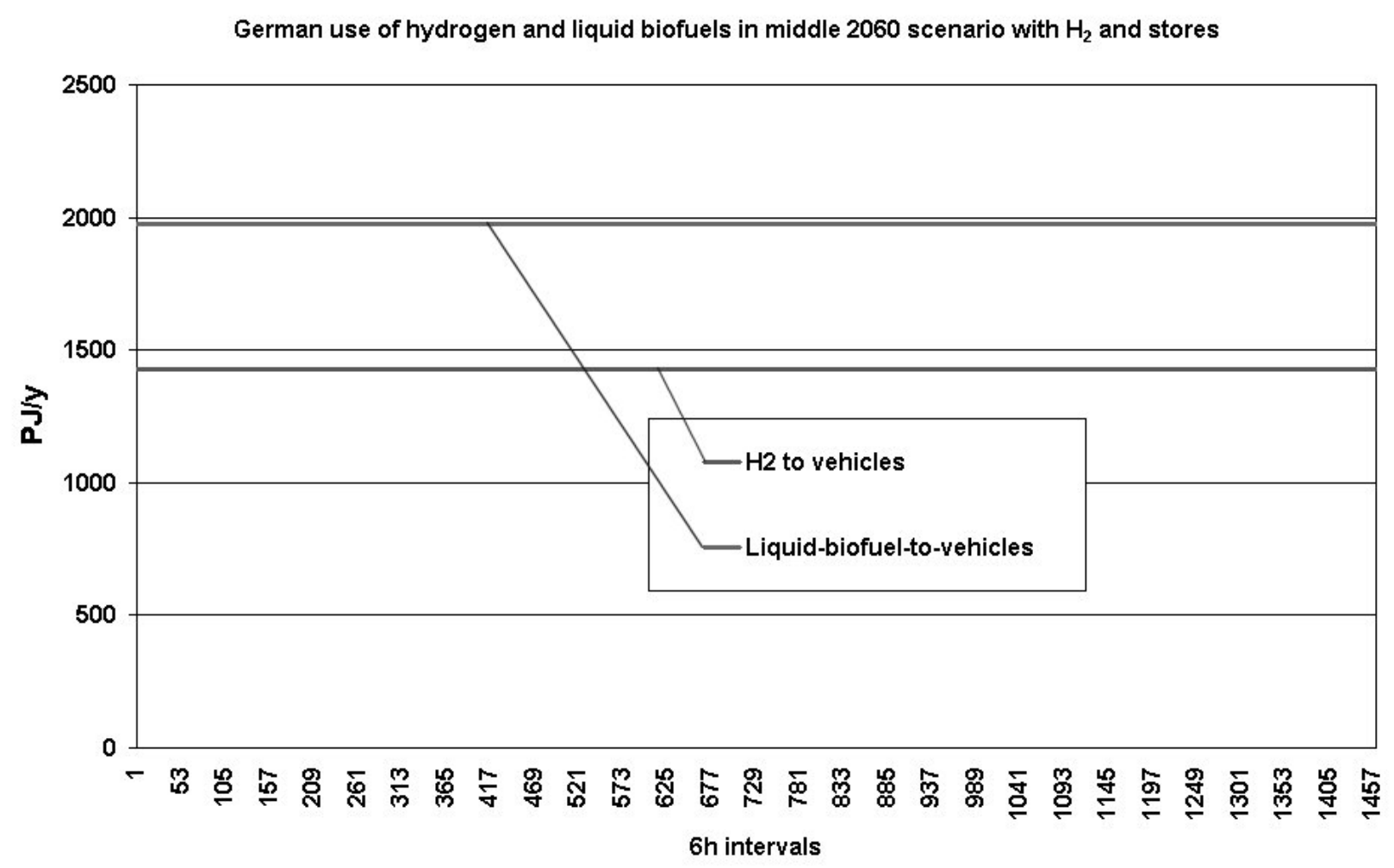

Figure 29. Disposition of fuels in the German 2060 scenario with full import options. The 50-50\% split between hydrogen and liquid biofuels can now be fully supported by the (large) supplemental combination of power and fuel imports.

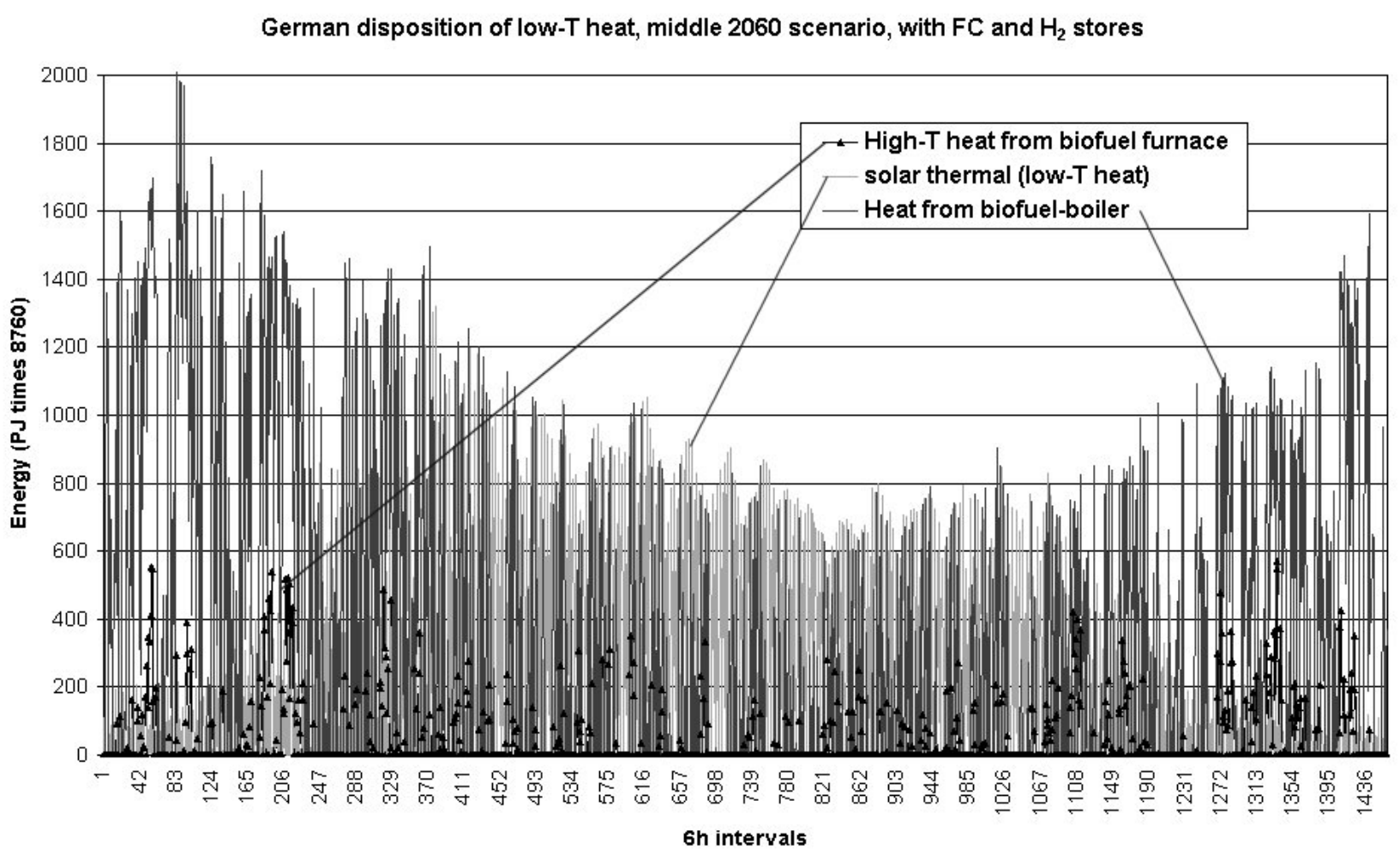

Figure 30. Disposition of low- and high-temperature heat in the German 2060 scenario with full import options. Cf. Fig. 21 for high-temperature heat in the case of an isolated Germany. 


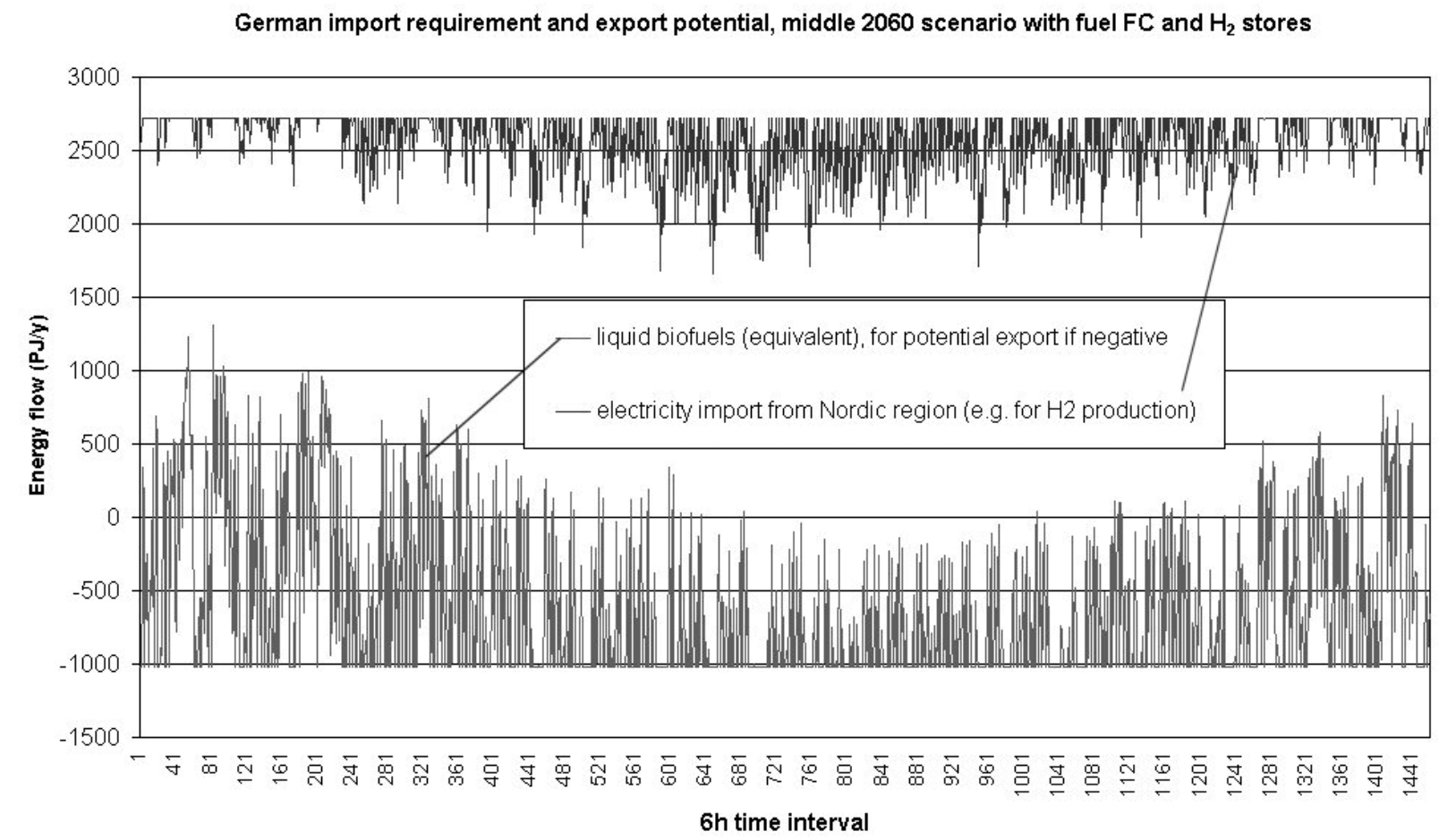

Figure 31. Import needs and export options for Germany in the 2060 scenario. The large import of surplus electricity from the Nordic countries makes the liquid fuel situation much more relaxed, with occasional periods of potential export and other periods of import, which can be seen to be avoidable by simply storing the biofuels.

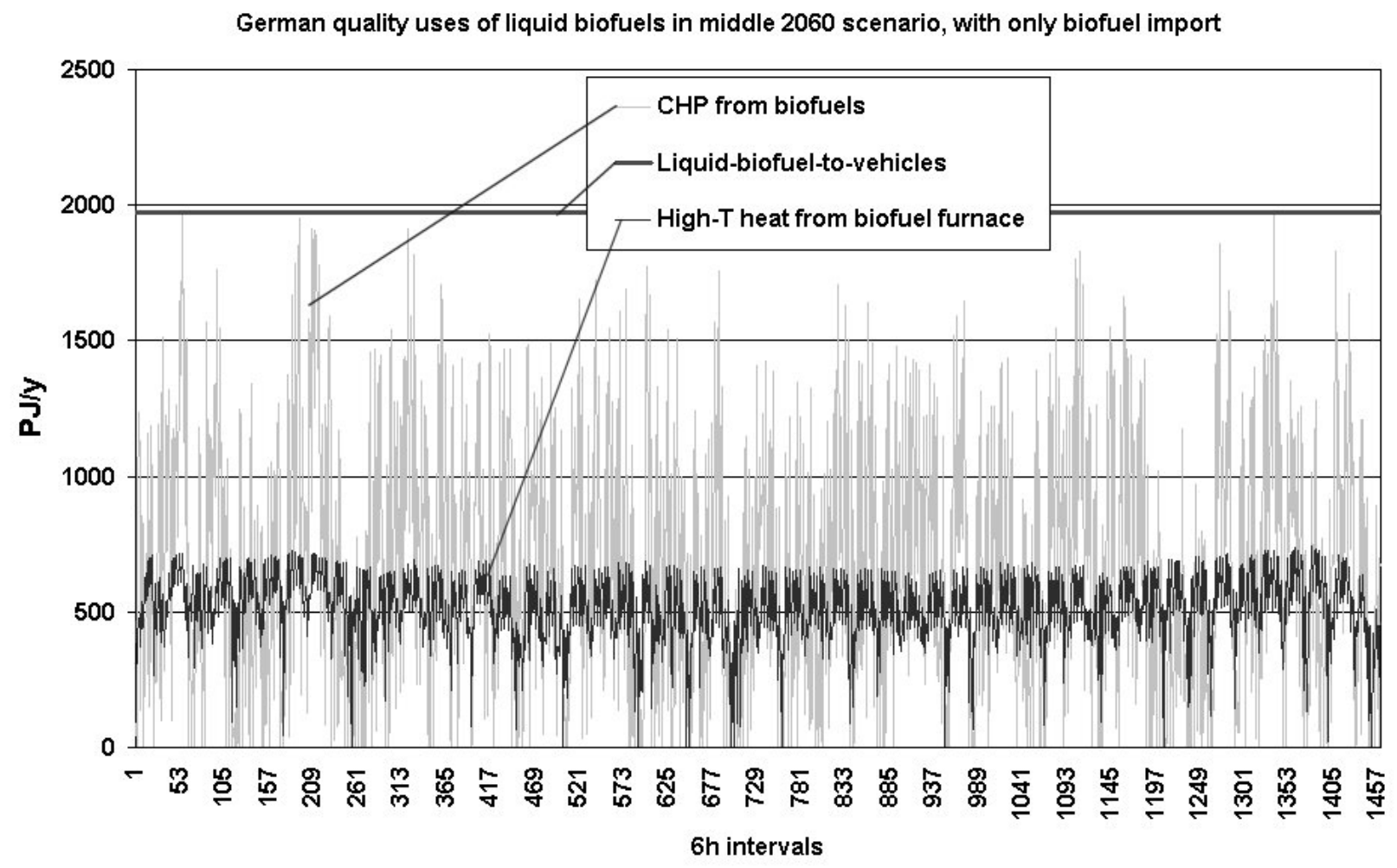

Figure 32. In the variant where Germany only imports biofuels by 2060, these are used to produce power in combined heat and power plants, when indigenous wind and hydro production is insufficient. Further uses of biofuels are for hightemperature process heat and vehicle fuels (now taking over much of the role played by hydrogen-fuelled fuel cellvehicles in the scenario where electricity imports were an option). 


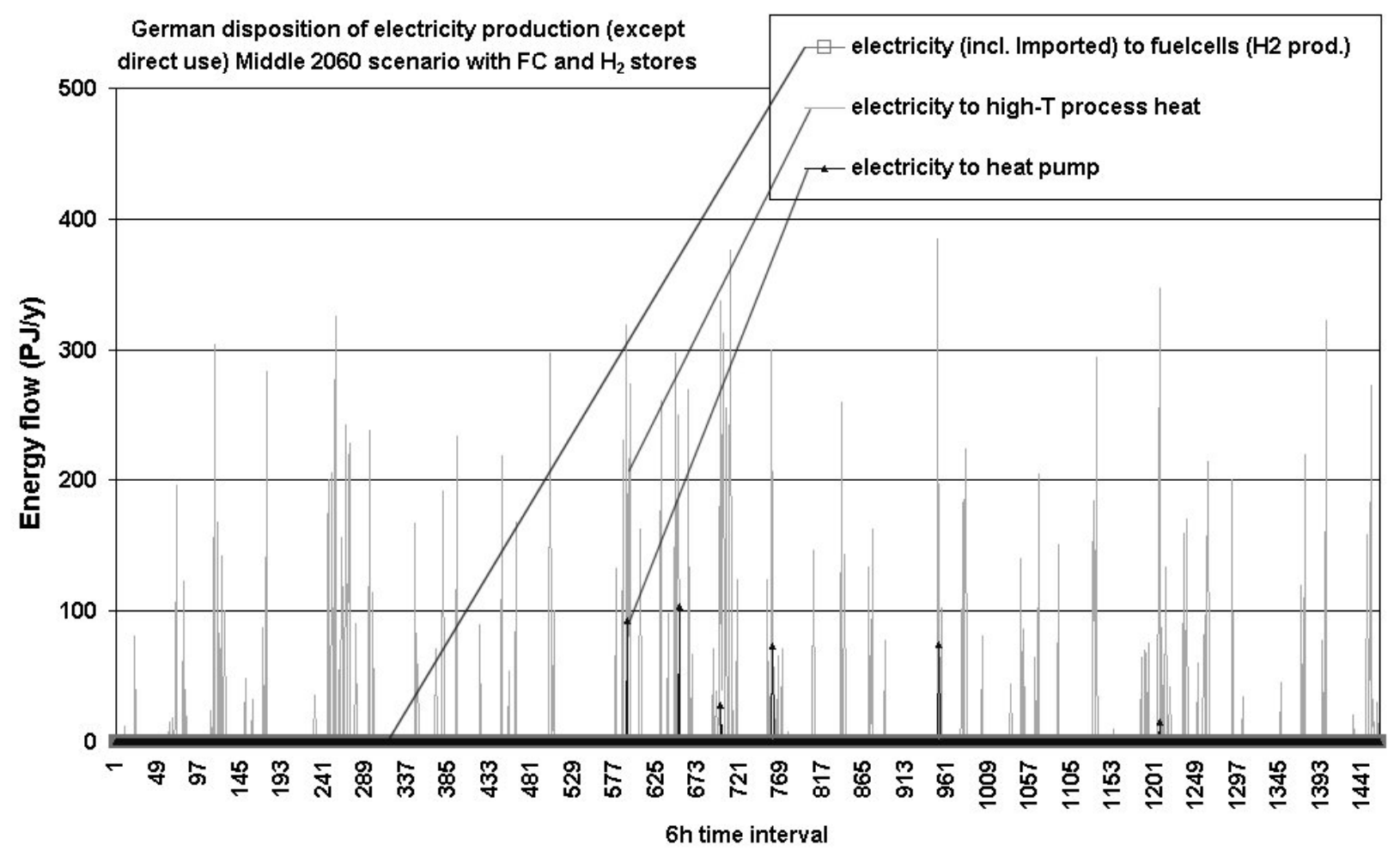

Figure 33. In the variant where Germany only imports biofuels by 2060, there is much less electricity available for hydrogen production and heat supply through furnaces and heat pumps. The balance must be supplied by biofuels, with the time distribution shown in Figure 32.

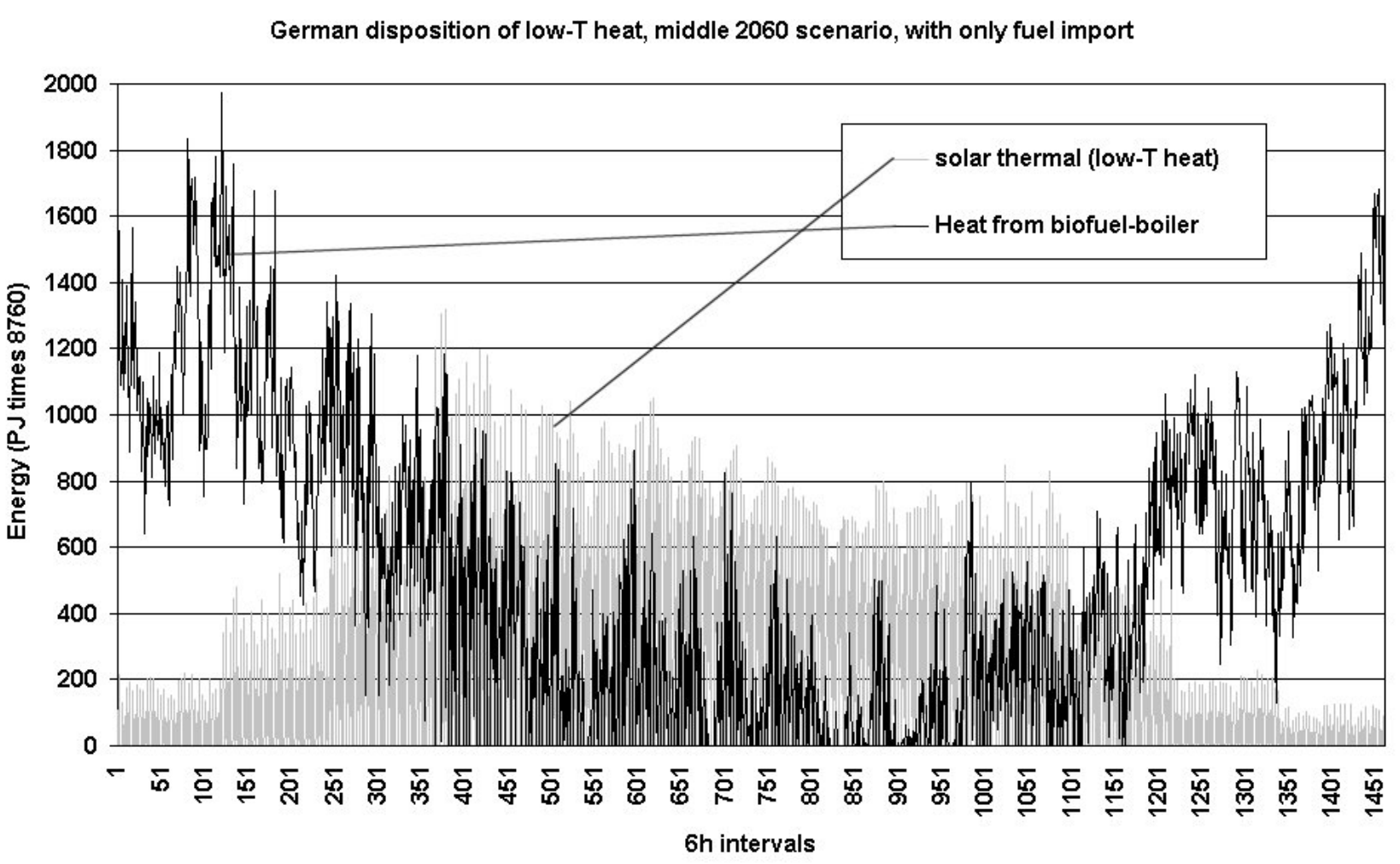

Figure 34. In the variant where Germany only imports biofuels by 2060, there are low-temperature heat demands that cannot be supplied by solar thermal collectors and must be covered by biofuels in boilers. 


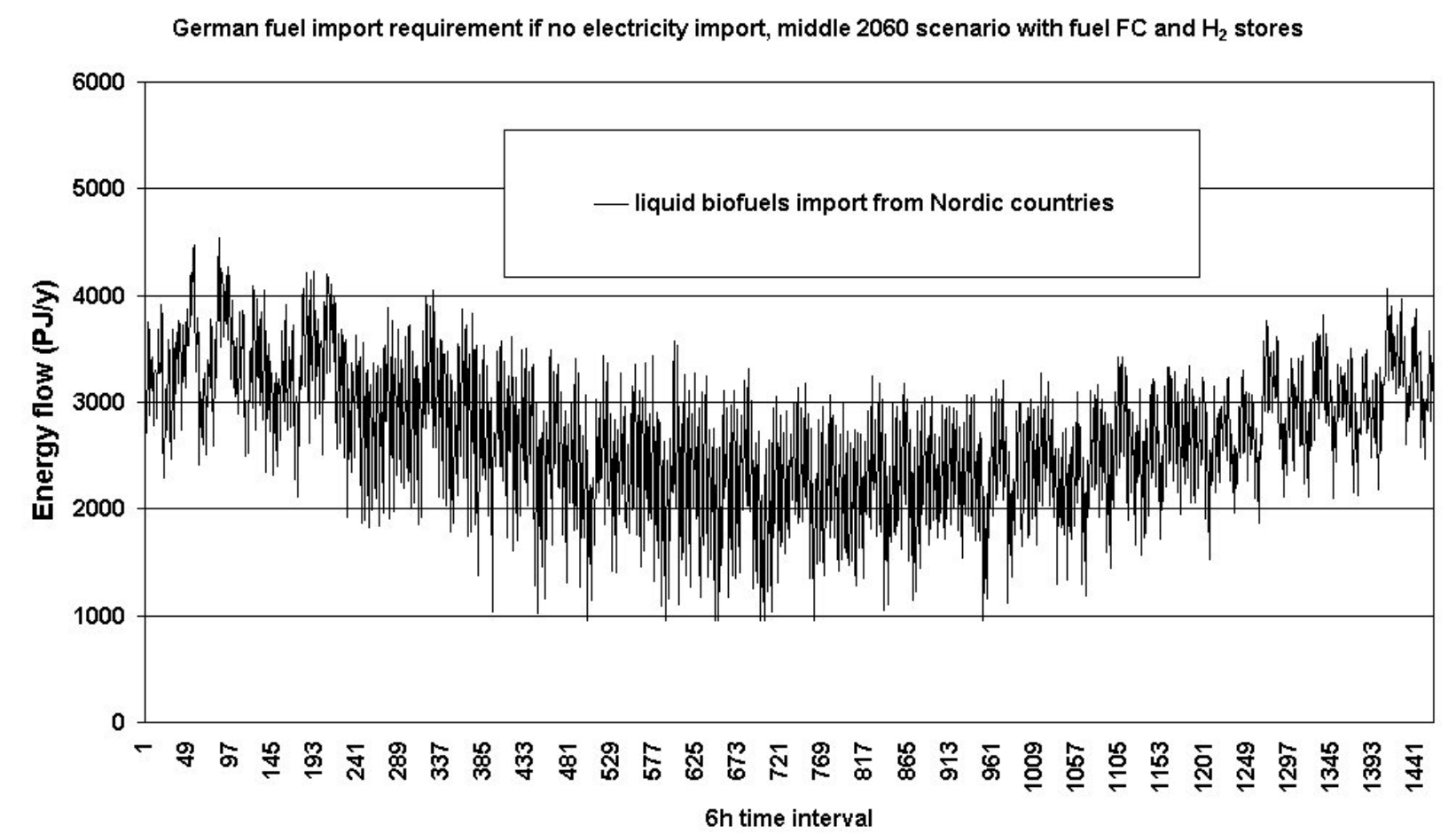

Figure 35. In the variant where Germany only imports biofuels by 2060, the total time series of biofuel import requirements is shown. Because biofuels may be stored, this need not coincide with the actual time distribution of imports. 